\title{
The potential roles of exosomes in pancreatic cancer initiation and metastasis
}

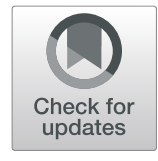

\author{
Wei Sun, Ying Ren, Zaiming Lu and Xiangxuan Zhao ${ }^{*}$ (D)
}

\begin{abstract}
Pancreatic cancer $(\mathrm{PaCa})$ is an insidious and highly metastatic malignancy, with a 5-year survival rate of less than $5 \%$. So far, the pathogenesis and progression mechanisms of PaCa have been poorly characterized. Exosomes correspond to a class of extracellular nanovesicles, produced by a broad range of human somatic and cancerous cells. These particular nanovesicles are mainly composed by proteins, genetic substances and lipids, which mediate signal transduction and material transport. A large number of studies have indicated that exosomes may play decisive roles in the occurrence and metastatic progression of $\mathrm{PaCa}$. This article summarizes the specific functions of exosomes and their underlying molecular mechanisms in mediating the initiation and metastatic capability of $\mathrm{PaCa}$.

Keywords: Exosome, Pancreatic cancer, Tumorigenesis, Metastasis, Tumor biomarker
\end{abstract}

\section{Background}

Pancreatic cancer (PaCa) ranks among the most common and devastating digestive tract cancers worldwide. Besides early surgical resection, no effective regime against this aggressive malignancy has been discovered so far [1]. The 5-year overall survival rate of $\mathrm{PaCa}$ is considered less than $5 \%$ and the survival period of advanced $\mathrm{PaCa}$ is only 3-6 months [2]. Remarkably, the carcinogenesis of $\mathrm{PaCa}$ remains poorly characterized. The majority of $\mathrm{PaCa}$ cases (over $85 \%$ ) are attributed to pancreatic ductal adenocarcinoma (PDAC) [3]. Some studies have shown that acinar-to-ductal metaplasia (ADM), induced by pancreatic injury, pancreatitis, or genetic toxicity, is one of the most typical events observed during $\mathrm{PaCa}$ development. ADM can further evolve into a variety of pancreatic intraepithelial neoplasias (PanINs), which are, to some extent, still reversible. Under the influence of many factors, PanINs eventually progress into PDAC [4]. ADM can be recovered after the elimination of oncogenic genetic insults or sustained

\footnotetext{
*Correspondence: xiangxuanzhao@163.com

Department of Radiology, Shengjing Hospital of China Medical University, 36 Sanhao Street, Heping District, Shenyang 110004, Liaoning, China
}

environmental stress [5]. It has been shown that matrix metalloproteinase-7 (MMP-7) [6], NAD (+) - dependent protein deacetylase sirtuin-1 (SIRT1) [7], and polycomb compressor complex 1 (PRC1) [8] are involved in the regulation of ADM development. In addition, atypical flat duct lesions (AFDL) have often been considered as precancerous conditions of $\mathrm{PaCa}$ [9]. Recent studies have also indicated that mutations on KRAS [10], m (6) A demethylase gene ALKBH5 [11], PDL-1 (CD274), and various non-coding RNAs [12] may play key roles in modulating the occurrence and development of $\mathrm{PaCa}$. Still, despite many reports describing a plethora of signal pathways involved in $\mathrm{PaCa}$ initiation and progression, the underlying mechanisms that orchestrate the development of this malignancy are poorly known or still under debate.

Exosomes, a general term for a particular class of nano-extracellular vesicles are produced by various stromal and transformed cells in the tumor microenvironment (TME) [13, 14]. Exosomes can be transported by a number of body fluids (i.e. blood, saliva, pancreatic duct fluid, cerebrospinal fluid and amniotic fluid) to distal tissues and organs, but, importantly, they can also function 
by autocrine and paracrine routes [15]. Exosomes can modulate the activation of various signaling pathways in target (recipient) cells. There is evidence showing that exosomes play crucial roles in the pathogenesis and evolution of many pancreas precancerous conditions, including diabetes mellitus (DM), pancreatitis, pancreatic fibrosis and other pancreatic-related disorders [16-18]. Exosomes can participate in promoting the transformation of various precancerous lesions to $\mathrm{PaCa}$, including intraductal papillary malignant neoplasm (IPMN) and PanIN but, moreover, they may also play major roles in PaCa metastasis by inducing angiogenesis, cell migration, epithelial-mesenchymal transition (EMT), and apoptotic resistance $[19,20]$. Our current work aims to discuss the biological significance of exosomes in PaCa carcinogenesis and metastasis.

\section{Exosome overview}

\section{Characteristics of exosomes}

Exosomes mainly consist of spherical, disc or cupshaped nanoparticles, coated by phospholipid bilayer, with a diameter of $40-150 \mathrm{~nm}$ (Fig. 1). These nanostructures typically contain proteins, nucleic acids, lipid molecules and other inorganic substances such as $\mathrm{Ca}^{2+}$ $[13,14]$. Although exosomes can be generated by various types of cells, they all share similar structural proteins, including Rab GTPases, major histocompatibility complex class I and class II molecules (MHC I/II), Annexins, ALG-2 interacting protein X (ALIX), tumor susceptibility gene 101 protein (TSG101), flotillin (FLOT1), integrins, and tetraspanins (Tspans) [21].

Tspans belong to a 4-transmembrane protein family, mainly comprised of CD9, CD63, CD81, CD82, CD53, and CD37, which are $\sim 100$-fold more enriched in exosomes than in their parental cells [22]. Homodimers can be formed between Tspans, or heterocomplexes can be formed between Tspans and other proteins. Tspans may also couple with cholesterol and gangliosides to further generate distinct Tspan-enriched microdomains (TEMs). Depending on the cellular requirements, TEMs may selectively recruit membrane-related proteins, such as

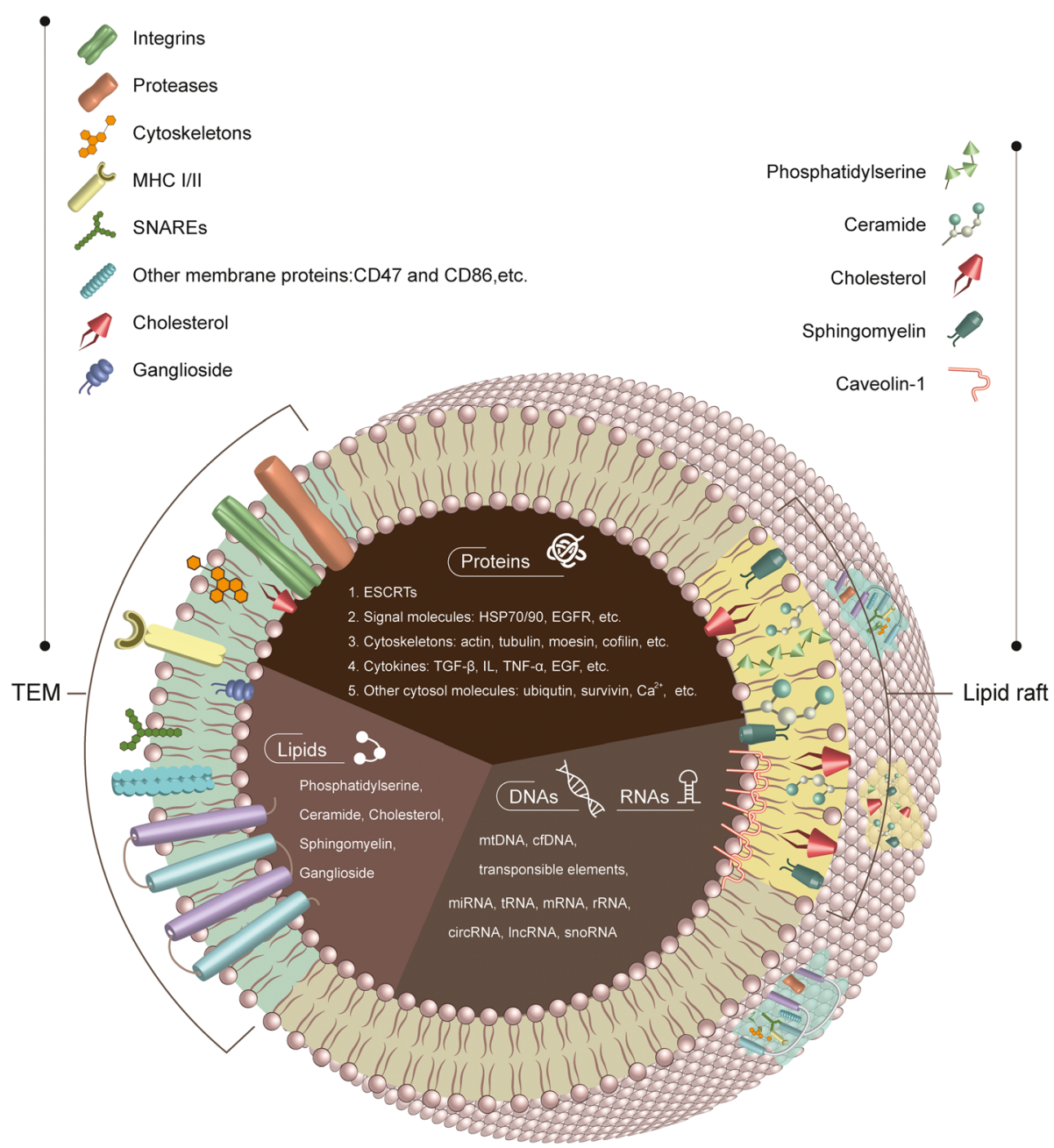

Fig. 1 The main features of exosome 
integrins, proteases and other related signal molecules, thus operating as a specific signal transduction platform [23].

The exosome surface also contains a variety of lipid raft microdomains such as caveolae that integrates caveolins as structural proteins that have a property to resist against detergents. These exosome microdomains (TEMS and caveolae) can transduce important signals, such as apoptosis and cell cycle arrest, via lipid molecules or proteins [24]. Exosomal lipids are comprised of cholesterol, ganglioside, sphingomyelin, (hexosyl) ceramide, phosphotidylserine, and phosphotidylethanolamine [25]. Exosomal nucleic acids mainly correspond to microRNAs (miRNAs/miRs), transfer RNAs (tRNAs), ribosomal RNAs (rRNAs), messenger RNAs (mRNAs), circular RNAs (circRNAs), long noncoding RNAs (lncRNAs), lincRNAs, cell free DNAs (cfDNAs) and mitochondrial DNAs (mtDNAs) [26]. According to the necessity of the cells, the protein content of certain exosomes may integrate particular signal molecules, including heat shock protein family proteins (such as HSP70/ 90), as well as cell membrane receptors (such as EGFR), cytokines, cytoskeletal molecules, and other cytosolic components such as ubiquitin, survivin, and $\mathrm{Ca}^{2+}[26]$. At the same time, the lipid membrane components as well as the inner exosomal content may vary according to the exosome function and the type of exosomeproducing cells.

\section{Exosome secretion and uptake}

Exosomes originated from early endosomes, formed by invaginations along the cell membrane. Upon stimulation by specific signals, early endosomes continually collect a variable amount of cargoes from the cytosol, leading to their maturation into late endosomes, i.e. multivesicular bodies (MVBs) containing a large number of intraluminal vesicles (ILVs) [27] (Fig. 2). The formation of ILVs is mainly mediated by an endosome sorting complex required for transport (ESCRT) complexdependent machinery [24]. MVBs can be transported to and fuse with the plasma membrane, culminating into the release of the internal ILV to the extracellular environment to form the so-called exosomes. MVBs can also fuse with lysosomes, by which their content is degraded

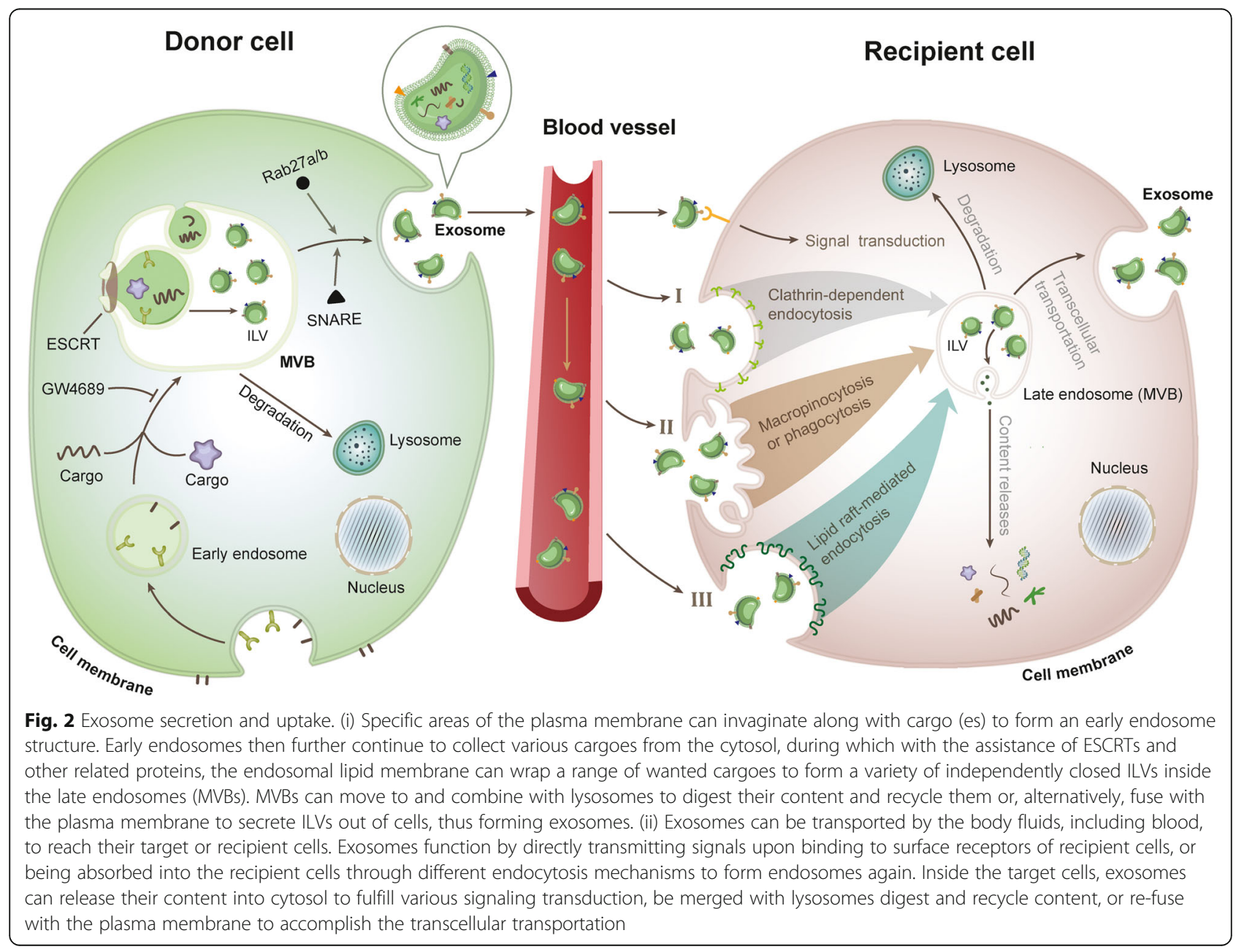


and recycled for further utilization. The movement and fusion of MVB to the plasma membrane is largely regulated by specific signaling pathways. It has been shown that soluble N-ethylmaleimide-sensitive factor attachment protein receptors (SNAREs) and GTPase Rab family proteins (such as Rab27a/b) are implicated in the process of MVB fusion to the plasma membrane $[28,29]$. Additionally, there is also evidence supporting that the formation of MVB does not depend on the existence of ESCRT complex. For instance, upon gene silencing of all ESCRTs (under the assistance of Tspans and ceramide), a large number of ILVs can still be formed in the MVB, which eventually move to the plasma membrane for further release of exosomes [30, 31]. GW4682, a smallmolecule compound, can reduce the production of ESCRT-independent exosomes by inhibiting neutral sphingomyelinase 2 (nSMase2), which then generates ceramide from sphingomyelin [32]. Upon delivery of exosomes into recipient cells via body fluids (such as blood), these biological nanocarriers interact with cells by recognition and conjugation to membrane-bound receptors, therefore activating specific signal pathways in target cells. Alternatively, exosomes can be also internalized into target cells by different mechanisms, including clathrin-dependent, lipid raft (Caveolae/caveolin-1)-mediated endocytosis, and macropinocytosis/ phagocytosis [33]. After entering the cells, MVBs (late endosomes) containing exosomes either fuse with lysosomes to recycle exosomal components, or release their content into the cytoplasm to further act as second messengers. Exosomes may also be secreted again from cells by mechanisms involving transcellular transport.

\section{Exosomes and $\mathrm{PaCa}$ initiation}

Pancreatitis and diabetes mellitus (DM) are both considered non-malignant pancreatic diseases that may promote abnormal secretion of hormones, such as glucagon increase and insulin decrease, and tissue destruction that could eventually evolve into $\mathrm{PaCa}$, if no preventive or therapeutic care is provided [34]. Furthermore, genetic mutations, obesity, viruses, and alcohol intake are also risk factors for PaCa occurrence $[35,36]$. PaCa can develop from pre-malignant lesions, such as intraductal papillary mucinous neoplasm (IPMN) or pancreatic intraepithelial neoplasia (PanIN). Meanwhile, some key pro-oncogenic factors, including KRAS, CDKN2A (also known as p16/MTS1), SMAD4, and p53, have been reported be involved in the transition of pre-cancerous conditions to $\mathrm{PaCa}$ [37]. In this section, we discuss how exosomes are closely associated with the onset of pancreas precancerous diseases (Table 1).

\section{Exosomes and pancreatitis}

Pancreatitis is usually divided into acute (AP), chronic $(\mathrm{CP})$, and autoimmune (AIP) pancreatitis. AP relates to an acute auto-digestive inflammatory reaction of the pancreatic tissue, which can lead into pancreatic edema, hemorrhage and eventually necrosis, or parenchymal cell apoptosis. Moreover, AP is often accompanied by local or systemic complications and is considered highly lethal. AP-induced $\mathrm{PaCa}$ may occur independently of age, country (or geographic region), and etiology [61, 62]. In contrast, $\mathrm{CP}$ is correlated with various pro-inflammatory pancreatic secretion diseases and fibrosis, thus increasing the risk of $\mathrm{PaCa}$ by 12 -fold $[41,63]$. Generally, the risk of $\mathrm{CP}$ to evolve into $\mathrm{PaCa}$ within a 20 -year range is $5 \%$, while the incidence of the disease increases annually thereafter [64]. Lastly, AIP is a distinct type of autoimmune pancreatic disease that is divided into diffuse and focal/segmental subtypes, whose correlation with $\mathrm{PaCa}$ is still unclear [65].

Increasing evidence has suggested that exosomes are involved in the occurrence, development of pancreatic inflammation (pancreatitis) as well as related carcinogenesis. Compared with healthy subjects, the number of circulating exosomes (cirExos) in the blood of AP patients (AP-cirExos) is significantly increased [66]. APcirExos appear to originate from liver or immune cells, and play a similar role as inflammatory factors by inducing a series of molecular reactions that may result in irreversible changes of interstitial fibrosis as well as parenchymal calcification of the pancreas [66]. APcirExos can break through the lung alveolar endothelial barrier and induce the transformation of macrophages from M2 to M1 to eventually promote an acute lung injury (ALI) [66]. Recent studies have indicates that APcirExos can induce the nucleotide binding oligomerization domain (NOD)-like receptor protein 3 (NLRP3)-dependent inflammasome activation and pyroptosis in alveolar macrophages of AP mouse model [67]. Moreover, AP can produce cirExos in ascites to further induce injury in other related tissues and organs via the hepatic or portal system [66]. In vivo studies using a rat model with taurocholate-induced AP have indicated that exosomes derived from pancreatitisassociated ascitic fluid (PAAF-Exos) and plasma exosomes (AP-cirExos) are two distinct populations. For instance, AP-cirExos exhibit much higher proinflammatory activity on macrophages than PAAF-Exos. One possible explanation for this difference is that the former contains some pro-inflammatory miRNAs such as miR-21/122/155, while the latter possesses high levels of histones and ribosomal proteins [68]. Klotho, an antiaging protein is overexpressed in several malignancies, including breast cancer [69] and hepatocellular carcinoma [70], to induce apoptotic resistance and cell growth. 
Table 1 Potential exosomes biomarkers involved in pancreas precancerous diseases

\begin{tabular}{|c|c|c|c|c|c|}
\hline Biomarkers & Sample & Receipt cell & Exosome function & $\begin{array}{l}\text { Clinical } \\
\text { significance }\end{array}$ & Refs \\
\hline $\begin{array}{l}\text { Calreticulin/Gp96/ } \\
\text { ORP150 }\end{array}$ & Islet $\beta$-cells & DCs & Increase activation of APCs & T1DM & {$[38]$} \\
\hline $\mathrm{CCN} 2 / \mathrm{miR}-21$ & PSCs & PSCs & $\begin{array}{l}\text { Stimulate the migration, proliferation, and division of PSCs as well as the } \\
\text { collagen and fibronectin secretion }\end{array}$ & $\mathrm{CP}$ & {$[39]$} \\
\hline FABP4 $\uparrow$ & Serum & $\begin{array}{l}\text { Not } \\
\text { mentioned }\end{array}$ & Exacerbate insulin resistance and result in hyperglycemia & $\mathrm{T} 2 \mathrm{DM}$ & {$[40]$} \\
\hline GAD65/IA-2/Pro-insulin & Islet $\beta$-cells & DCs/T-cells & Decrease $\beta$-cell content and insulin secretion & T1DM & {$[38]$} \\
\hline Klotho & MSCs & PACs & Block inflammatory responses and apoptosis & AP & {$[41]$} \\
\hline RBP4 & Adipocytes & Macrophages & Stimulate macrophages to secrete IL-6 or TNF- $a$ & $\mathbb{R}$ & {$[42]$} \\
\hline TAAs $\uparrow$ & Serum & $\begin{array}{l}\text { B } \\
\text { lymphocytes }\end{array}$ & Prevent B lymphocytes from recognizing PaCa cells & IS & $\begin{array}{l}{[43-} \\
45]\end{array}$ \\
\hline MiR-16 & SKMs & Islet $\beta$-cells & Inhibit $\beta$-cell proliferation & IR and T2DM & {$[46]$} \\
\hline $\begin{array}{l}\text { MiR-16-5p/574-5p/21- } \\
5 p \downarrow\end{array}$ & Serum & $\begin{array}{l}\text { Not } \\
\text { mentioned }\end{array}$ & Not mentioned & T1DM & {$[47]$} \\
\hline MiR-30/133b/342 $\uparrow$ & Urine & Adipocytes & Not mentioned & $\mathrm{T} 2 \mathrm{DM}$ & {$[48]$} \\
\hline MiR-106b-5p/222-3p-c & BMCs & Islet $\beta$-cells & Induce $\beta$-cells proliferation & T1DM & {$[49]$} \\
\hline MiR-142-3p/142-5p/155 & $\begin{array}{l}\text { T } \\
\text { lymphocytes }\end{array}$ & Islet $\beta$-cells & Induce apoptosis in $\beta$-cells & T1DM & {$[50]$} \\
\hline MiR-146a/b/195/497 & $\begin{array}{l}\text { Islet tumor } \\
\text { cells }\end{array}$ & $\begin{array}{l}\text { Islet tumor/ } \\
\beta \text {-cells }\end{array}$ & Induce apoptosis in islet tumor cells and $\beta$-cells & $\mathrm{T} 2 \mathrm{DM}$ & {$[51]$} \\
\hline MiR-155/222/486 & ADCs & $\begin{array}{l}\text { Not } \\
\text { mentioned }\end{array}$ & Not mentioned & $\mathrm{DM}$ & $\begin{array}{l}{[52-} \\
54]\end{array}$ \\
\hline MiR-203 & PaCa cells & DCs & inhibit the expression of TLR4, TNF- $a$, and IL-12 & IS & {$[55]$} \\
\hline MiR-212-3p & PaCa cells & DCs & Inhibit DCs from presenting antigens to T lymphocytes & IS & {$[56]$} \\
\hline MiR-375 $\uparrow$ & Serum & $\begin{array}{l}\text { Not } \\
\text { mentioned }\end{array}$ & Reduce insulin secretion and islet formation & $\mathrm{T} 2 \mathrm{DM}$ & $\begin{array}{l}{[57,} \\
58]\end{array}$ \\
\hline MiR-1260a/494-3p & ${ }^{*} \mathrm{PaCa}$ cells & iPBMCs & Not mentioned & IS & {$[59]$} \\
\hline $\begin{array}{l}\text { IncRNA ENST/mRNA } \\
\text { AEP/legumain }\end{array}$ & PaCa cells & DCs & Not mentioned & $\begin{array}{l}\text { Not } \\
\text { mentioned }\end{array}$ & {$[60]$} \\
\hline
\end{tabular}

$\uparrow$, up-regulation; $\downarrow$, down-regulation

Abbreviations: $A D C s$ adipose derived macrophages, MSCs mesenchymal stem cells, BMCs bone marrow cells, iPBMCs immunosuppressive peripheral blood mononuclear cells, IR insulin resistance, IS immune suppression, IncRNA ENST IncRNA ENST00000560647, NF-KB nuclear factor-kB, *PaCa cells SMAD4 ${ }^{-1-}$ pancreatic cancer cells, PAC pancreatic acinar cells

Interestingly, exosomal Klotho derived from mesenchymal stem cells (MSCs) can attenuate the caeruleininduced activation of the nuclear factor- $\mathrm{kB}(\mathrm{NF}-\mathrm{kB})$ signaling in pancreatic acinar cells, which potentially block inflammatory responses and apoptosis in AP. These observations suggest that exosomal Klotho could be utilized as a potential therapeutic target for AP [41].

Repeated episodes of AP can eventually evolve into CP. There are many pathogenic factors identified for $\mathrm{CP}$, which is mainly characterized by a slow but progressive pancreatic tissue destruction and fibrosis that increase the risk of $\mathrm{PaCa}$ [71]. Indeed, $\mathrm{CP}$ can cause some substantial pancreatic tissue destruction as well as exocrine/ endocrine insufficiency, which potentially activate resting pancreatic stellate cells (PSCs). The activated PSCs have a high proliferation capacity, which can be transformed into myofibroblasts [72, 73]. PSCs are able to communicate with PanINs and promote their progression [74, 75]. It has been shown that connective tissue growth factor 2 (CCN2/CTGF2), a fibrosis-related protein, can modulate a multitude of pancreatic cell functions, such as $\beta$-cell proliferation and fibronectin secretion in PSCs [71]. Clinical studies have also shown that CCN2 is highly expressed in PSCs from CP patients [39]. Mechanistic analyses have demonstrated that CNN2 expression can be regulated by miR-21 [39]. Moreover, both CCN2 and miR-21 are found in exosomes produced by PSCs [39]. In vivo studies using a mouse alcoholic pancreatitis model have demonstrated that miR-21- and CCN2-positive exosomes can be retrieved by other PSCs in an autocrine or paracrine manner, therefore stimulating the migration, proliferation, division of PSCs as well as the collagen production [39]. These continuously activated PSCs-secreted collagens 
may precipitate and form extensive fibrotic lesions in pancreas. Clinically, a higher density stroma or the induction of fibrotic plaques by PSCs is typical characteristics of both $\mathrm{CP}$ and $\mathrm{PaCa}$. These coincident features make these two pathological conditions hardly distinguishable [39].

Additionally, Zhao and coworkers have shown that rat pancreatic acinar cells can also produce exosomal miRNAs that are capable of activating pancreatitisassociated macrophages via MAPK signaling pathway [76]. However its physiological significance remains to be verified. Many viruses, including hepatitis viruses [77], human immunodeficiency virus [78], epstein-barr virus, [79] and coxsackie virus [80], can also cause pancreatitis. Among these viruses, coxsackie virus B3 (CVB3) infection has been reported to induce an increase on the levels of intracellular $\mathrm{Ca}^{2+}$ as well as cytoskeleton depolymerization in host cells, promoting the secretion of CVB3-positive exosomes that may propagate virus transmission upon uptake by non-infected cells. Of note, alcohol consumption has been referred to increase the incidence of CVB3-induced pancreatitis [81].

\section{Exosomes and diabetes mellitus (DM)}

$\mathrm{DM}$ is a metabolic disease driven by genetic and/or environmental factors [82]. DM-mediated fat toxicity, chronic inflammation, and oxidative stress may modify the function of a number of cells, such as pancreatic $\alpha /$ $\beta$-cells, adipocytes, hepatocytes, and T-lymphocytes, and then increase the risk of $\mathrm{PaCa}$ [83]. There is also evidence indicating that the incidence of $\mathrm{PaCa}$ is significantly higher in DM patients than in the normal population, for which, one possible explanation is that insulin resistance and abnormal glucose metabolism can act as driving forces behind $\mathrm{PaCa}$ predisposition in $\mathrm{DM}$ patients [82]. In addition, blood glucose levels have been correlated with the prevalence of $\mathrm{PaCa}$ [67], besides serving as a predictor of tumor size and grading in $\mathrm{PaCa}$ patients [84].

Recent studies have shown that exosomes also mediate Type 1 DM (T1DM, mainly caused by autoimmune reaction) [85] and Type 2 DM (T2DM) [86]. Specifically, Delong and coworkers have found that exosomes appear to play crucial roles in islet autoimmune response in T1DM [87]. Antigen presenting cells (APCs)-derived exosomes contain large amounts of major histocompatibility complex (MHC), which are able to induce the Tcell immune response and activate B lymphocytes to initiate humoral immunity. These responses may specifically support the generation of an autoimmune attack towards islet $\beta$-cells, resulting in a decrease of $\beta$-cell content and eventually an increase in blood glucose levels and DM due to limited insulin secretion [38, 88]. Cianciaruso and colleagues have observed that exosomes released by both human and rat pancreatic islets contain $\beta$-cell autoantigens, such as glutamin acid decarboxylase 65 (GAD65), insulinoma-associated protein 2 (IA-2), and pro-insulin. These particular exosomes are also capable of entering and activating dendritic cells (DCs) [38]. Upon endoplasmic reticulum stress (ERS), T1DMrelated cytokines, including IL- $1 \beta$ and IFN- $\gamma$, can induce $\beta$-cells to release exosomes containing calreticulin, heat shock protein Gp96, and oxygen-regulated protein 150 (ORP150) to further exacerbate T1DM-related autoimmune diseases [38]. Besides exosomal proteins, it has also been reported that certain miRNAs, including miR142-3p, miR-142-5p, and miR-155, are specifically present in exosomes derived from murine and human $\mathrm{T}$ lymphocytes, which can promote apoptosis by upregulating T1DM-related chemokines (i.e. Ccl2, Ccl7, and Cxcl10) in pancreatic $\beta$-cells [50]. Furthermore, Tsukita and colleagues have confirmed that miR-106b$5 \mathrm{p}$ - and miR-222-3p-containing exosomes, produced by bone marrow cells, can enter $\beta$ cells to reduce CIP/KIP expression, resulting in $\beta$ cell proliferation in vitro and in vivo [49]. Specifically exosomal miR-106b-5p and miR-222-3p can rescue streptozotocin-induced apoptosis of $\beta$ cells in a mouse model, thus improving hyperglycemia [49]. Hence, exosomal miR-106b-5p and miR222-3p may be exploited as potential therapeutic agents for DM. Finally, serum levels of exosomal miR-16-5p, miR-574-5p and miR-21-5p are significantly higher in healthy subjects when compared to T1DM patients [47], but their significance in $\mathrm{PaCa}$ initiation still require further validation.

T2DM is mainly caused by insulin resistance, decreased hormonal sensitivity, or reduced insulin production due to pancreatic $\beta$-cell dysfunction. Fatty acidbinding protein 4 (FABP4) is released by adipose tissues and may play a key role in the development of T2DM [89]. Upon enhancement of lipolysis in obese T2DM patients, the amounts of exosomal FABP4 in plasma also increase, exacerbating insulin resistance and then resulting in hyperglycemia and T2DM [40]. Additionally, miRNA-positive exosomes, produced by pancreatic islets, have been found to trigger elevated $\beta$-cell apoptosis in T2DM. For instance, Guay and colleagues have treated MIN6 pancreatic islet tumor cells with IFN- $\gamma$, TNF- $\alpha$, and IL-1 $\beta$, and found that exosomal miR-146a/ b, miR-195, or miR-497, which are produced in response to treatment, can induce apoptosis in MIN6 cells as well as in mouse pancreatic islet cells [51]. MiR-375 plays an important role in maintaining glucose homeostasis [90]. It has been observed that overexpression of miR-375 suppresses glucose-induced insulin production in pancreatic $\beta$-cell lines and isolated primary $\beta$ cells. In contrast, this overexpression can be abrogated by miR-375 inhibition or myotrophin gene silencing [91, 92]. 
Importantly, serum miR-375-3p-positive exosomes derived from the pancreas have been shown to mediate a reduction on insulin secretion and islet formation, which eventually results in T2DM $[57,58]$. Still, miR-30, miR133b, and miR-342 are apparently up-regulated in urinary exosomes isolated from T2DM patients [48]. Exosomes enriched with miRNAs, such as miR-155 [52], miR-222 [53], and miR-486 [54] (isolated from adiposederived macrophages as well as MSCs and stem cells respectively), can act as potential modulators of DM. Nevertheless, the association between these exosomal miRNAs produced by adipose-derived cells and $\mathrm{PaCa}$ occurrence still requires further validation. Finally, miR200 overexpression induces $\beta$-cell apoptosis, which may contribute to T2DM-related death [93]. Whether miR200 is localized in exosomes also requires further evaluation.

\section{Exosomes-mediated immune suppression}

Exosomes produced by cancer cells can support their escape of immune surveillance by inhibiting lymphocyte activation and survival, and inducing loss of function in lymphocytes [94]. Of all, DCs are the most important APCs in the human body, functioning in the immune system by inducing the expression of Toll-like receptors (TLRs) and producing various interleukins (ILs). Among TLRs, TLR4 expression is particularly vital for the antitumor activity of DCs [95]. Exosomes produced by $\mathrm{PaCa}$ cells (PaCaExos) have been shown to induce immune suppression by deregulating DCs. For instance, miR203-containing exosomes produced by $\mathrm{PaCa}$ cells are able to increase intracellular miR-203 levels and inhibit the expression of TLR4,TNF- $\alpha$, and $I L-12$ after being uptaken by DCs, and eventually induce their dysfuction [55]. It has also been shown that miR-212-3p-positive PaCaExos can specifically diminish the levels of MHC II transcription factor and regulatory factor $\mathrm{x}$-associated protein (RFXAP) and, subsequently, inhibit DCs from presenting antigens to $\mathrm{T}$ lymphocytes [56]. Generally, exosomes containing tumor-associated antigens (TAAs), produced by cancer cells, can present MHC complexes to DCs for further processing and then activate the immune response by tumor-specific $\mathrm{T}$ lymphocytes [43, 44]. However, tumor cells are also shown to suppress both adaptive and innate antitumor responses via exosomes. As an example, the lipid membrane surface of cirExos from the plasma of $\mathrm{PaCa}$ patients contains a large amount of TAAs. These exosomes can specifically bind and harbor immunoglobulins in the plasma to prevent $\mathrm{B}$ lymphocytes from recognizing tumor cells, thereby enabling cancer cells to escape from the cytotoxic killing effects induced by immune cells [45]. In vivo studies have further confirmed that PaCaExos can effectively inhibit IL-2-mediated PI3K/Akt signal pathway in lymphocytes after being acquired by DCs and macrophages, which may eventually promote apoptosis [96]. Moreover, PaCaExos can increase the levels of lncRNA ENST00000560647 and asparaginyl endopeptidase (AEP/legumain) mRNA in DCs [60]. However, the precise function of these exosomes in immune escape needs to be further investigated.

Integration into a specific tumor microenvironment (TME) is considered a pre-requisite for cancer cell metastasis, proliferation, and survival. The formation of this microenvironment includes the transformation of immune cells (towards a immunosuppressive and protumor phenotype) as well as fibroblast proliferation and increased fiber hyperplasia [97]. There is evidence demonstrating that, in PaCa TME, the amount of immunosuppressive $\mathrm{T}_{\text {reg }}$ cells, M2 polarized tumor-associated macrophages (M2TAM), and immature myeloid-derived suppressor cells (iMDSCs) are superior to those of immune effective $\mathrm{CD}^{+} \mathrm{T}$ cells, DCs, and $\mathrm{M} 1$ polarized TAMs $[98,99]$. In this context, the immunosuppressive cells may help $\mathrm{PaCa}$ cells to escape immune surveillance. Notably, $\sim 50 \%$ of $\mathrm{PaCa}$ cases lack expression of the tumor suppressor SMAD4 [100]. SMAD4-deficient PaCa cells can produce exosomes that contain miR-1260a and miR-494-3p. Upon uptake by immunosuppressive peripheral blood mononuclear cells (such as gMDSCs and mMDSCs), these miR-1260a and miR-494-3p-positive exosomes can promote cell proliferation and glycolysis, thereby creating an immunosuppressive TME [59]. There is also evidence that exosomes produced by $\mathrm{PaCa}$ cells in rats can be uptaken by various leukocytes, leading to the inhibition of cell proliferation and weakness of anti-apoptotic ability. Moreover, these particular $\mathrm{PaCa}$ exosomes are capable of inhibiting IL-12-induced $T_{h}$ cell proliferation and abrogate the chemotactic migration of leukocytes to tumor sites [96], which contributes to TME formation.

\section{Exosomes-mediated metabolic disorders}

Accumulating evidence has demonstrated that obesity caused by high fat/caloric diet, contributes to $\mathrm{PaCa}$ initiation, especially in Western countries [101-103]. It has been shown that exosomes derived from adipose tissue of obese B6 mice can induce the differentiation of peripheral blood monocytes into activated macrophages [42]. Functional analyses have demonstrated that adipose tissues are capable of producing retinol binding protein 4 (RBP4)-positive exosomes to stimulate activated macrophages that secrete IL- 6 or TNF- $\alpha$ in a TLR4dependent manner, thus eventually inducing insulin resistance [42]. In addition, the impact of palmitic acid, isolated from edible palm oil, on metabolic diseases like DM has attracted great attention from cancer biologists. For instance, it has been discovered that mice fed with a 
high palmitic acid diet (HPAD) exhibit a subset of metabolic symptoms including hyperglycemia, glucose intolerance, and insulin resistance. Furthermore, HPAD can promote myoblasts to produce more exosomes that, in turn, may induce skeletal muscle (SKM) cell differentiation [104, 105]. Specifically, HPAD is capable of stimulating SKM to produce miR-16-positive exosomes that can be uptaken by pancreatic $\beta$-cells, thus inhibiting $\beta$-cell proliferation. This cell growth inhibition is driven by the activation of intracellular Hedgehog-PTCH1 signaling pathway that may, ultimately, induce SKM insulin resistance and promote T2DM progression [46]. Therefore, SKM-specific exosomes exert both endocrine and paracrine effects that may lead to insulin resistance due to the reduction of $\beta$-cell content.

Obstructive sleep apnea (OSA) is known as a potential cause of intermittent hypoxia (IH). Remarkably, this condition appears to increase the risk of cancer, promote cancer progression, and also elevate cancer-related mortality. Specifically, IH is shown to promote tumor cell proliferation and angiogenesis by increasing the production of exosomes and regulating exosome content [106, 107]. Almendros and colleagues have demonstrated that chronic intermittent hypoxia $(\mathrm{CIH})$ may increase the number of tumor-promoting exosomes in the blood. Compared with normal sleep populations (or treated OSA patients), serum exosomes derived from OSA patients can significantly promote the proliferation and migration of PaCa cells [108].

\section{Exosomes and PaCa metastasis}

Extensive evidence has demonstrated that tumor-derived exosomes act as extracellular signalosomes, with roles involving TME remodeling [109]. On one hand, PaCaExo can transport nucleic acids, proteins, or lipids from parental to recipient cells, which induce proinflammatory activities, mediate vascular leakiness, suppresses immune response, regulate apoptotic resistance, and promote angiogenesis and proliferation, thereby facilitating tumor metastasis. On the other hand, $\mathrm{PaCa}$ related cells such as cancer-associated fibroblasts (CAFs), tumor-associated macrophages (TAMs), cancer initiating cells (CICs) and PSCs generate exosomes that may promote growth, proliferation, drug resistance, EMT, migration, invasion and metastasis of $\mathrm{PaCa}$ cells (Table 2).

\section{PaCa-produced exosomes and PaCa metastasis PaCa exosomal proteins}

$\mathrm{PaCa}$-derived exosomes ( $\mathrm{PaCaExos})$ contain various protein molecules that can activate surrounding stromal cells and induce extracellular matrix (ECM) remodeling and neovascularization, thus establishing a TME to facilitate metastasis. In vivo studies using $\mathrm{PaCa}$ animal models have demonstrated that PaCaExos are rich in Tspan8, CD106, and CD49d [118]. Upon uptake by rat aortic epithelial cells (ECs), those PaCaExos activate the intracellular expression of $V W F$ (von Willebrand factor), TSPAN8, CXCL5, MIF (migration inhibitory factor), CCR1, VEGF and VEGFR2, which lead to neovascularization by inducing EC proliferation, migration, sprouting, and progenitor maturation. Notably, Tspan8enriched exosomes produced by $\mathrm{PaCa}$ cells can induce VEGF-independent angiogenesis around tumor tissues [118]. Costa Silva and colleagues have pointed out that $\mathrm{PaCa}$ can utilize exosomes to establish a pre-metastatic niche in distal organs, such as liver or lungs [130]. In this case, after exosomes derived from mouse $\mathrm{PaCa}$ cells were injected into healthy mice, they could be found in the liver [130]. Mechanistic analysis have shown that MIF-positive exosomes derived from $\mathrm{PaCa}$ cells can promote liver metastasis by increasing TGF- $\beta$ expression in Kupffer cells (KCs) and also activating hepatic stellate cells (HSCs) to secret fibronectin [130]. Compared with healthy subjects or individuals with 5-year progressionfree $\mathrm{PaCa}, \mathrm{PaCa}$ patients with liver metastases usually exhibit elevated exosomal MIF levels in the serum [116]. Therefore, exosomal MIF may prominently function in the formation of the liver pre-metastatic niche. Additional evidence has demonstrated that PaCaExos that are positive for integrin $\alpha v \beta 5$ usually reach the liver, whereas integrin $\alpha 6 \beta 4$ - and $\alpha 6 \beta 1$-containing exosomes are transported to the lungs [116]. A recent study has demonstrated that protein kinase D1 (PRKD-1) expression is significantly downregulated in $\mathrm{PaCa}$ tissues when compared to non-tumor tissues [131]. Particularly, PRKD-1 knockout can induce PaCa cells (Panc-1) to produce more exosomes. Moreover, $\mathrm{PaCa}$ xenograft mouse experiments have confirmed that PRKD-1 knockout can increase the content of exosomes in the serum, thus promoting $\mathrm{PaCa}$ invasion. Mechanistic analysis has showed that alteration on PRKD-1 may stimulate $\mathrm{PaCa}$ cells to produce more integrin $\alpha 6 \beta 4$ positive exosomes to promote $\mathrm{PaCa}$ lung metastasis [131]. Furthermore, $\mathrm{Li}$ and colleagues have figured out that the formation of a pre-metastatic niche also requires the generation of new blood vessels [128]. Upon uptake by human umbilical vein endothelial cells (HUVECs), PaCaExos can activate Akt and ERK1/2 signaling pathways. This pathway activation promotes tube formation, by increasing Ras homolog gene family member A (RhoA) activity, as well as cytoskeleton remodeling, which drive a cell shrinkage due to the decreased expression of tight junction ligand protein Zonula occludens-1 (ZO-1), and also induce endothelial barrier dysfunction by enhancing local hyperpermeability [128]. In another study, Satake and colleagues have injected double fluorescence-labeled Mia-PaCa-2 cells into the spleen of nude mice and then 
Table 2 Potential exosomes biomarkers involved in PaCa metastasis

\begin{tabular}{|c|c|c|c|c|c|}
\hline Biomarkers & Sample & Target cell & Exosome function & Signaling pathway & Refs \\
\hline CD44v6 & $\mathrm{hPaCa}-\mathrm{CM}$ & $\mathrm{hPaCa}$ cells & Enhance migration and invasion & $\begin{array}{l}\text { Activate Wnt/ß-Catenin pathway and increase } \\
\text { PAl-1, MMP and TIM-1 }\end{array}$ & {$[110]$} \\
\hline $\begin{array}{l}\text { CD151/ } \\
\text { Tspan8 }\end{array}$ & $\mathrm{rPaCa}-\mathrm{CM}$ & $\mathrm{hPaCa}$ cells & $\begin{array}{l}\text { Promote EMT, migration and metastasis, and } \\
\text { increase drug resistance }\end{array}$ & $\begin{array}{l}\text { Increase expression of chemokine and receptor } \\
\text { such as CXCR4 and EGFR3 }\end{array}$ & $\begin{array}{l}{[111} \\
112]\end{array}$ \\
\hline Claudin7 & $\mathrm{rPaClC}$ & $\mathrm{hPaCa}$ cells & Promote migration and invasion & $\begin{array}{l}\text { Increase pAkt/BCl-2/BCl-XL /MDR1, promote } \\
\text { matrix degradation, and reprogram SC and HPC }\end{array}$ & [113] \\
\hline $\begin{array}{l}\text { ICAM-1/ } \\
\text { AA }\end{array}$ & $\mathrm{hPaCa}-\mathrm{CM}$ & Macrophage & $\begin{array}{l}\text { Induce macrophage phenotype change and } \\
\text { promote tumor growth }\end{array}$ & $\begin{array}{l}\text { Increase VEGF, MCP-1, IL-6, IL-1 } \beta, \text { MMP-9 and } \\
\text { TNF-a }\end{array}$ & [114] \\
\hline $\operatorname{Lin} 28 B$ & hPaCa-CM & $\mathrm{hPaCa} / \mathrm{PSC}$ & Promote metastatic invasion & Activate Lin28B/let-7/HMGA2/PDGFB axis & {$[115]$} \\
\hline MIF & $\begin{array}{l}\mathrm{m} / \mathrm{hPaCa}- \\
\mathrm{CM}\end{array}$ & $\mathrm{KC} / \mathrm{HSC}$ & $\begin{array}{l}\text { Promote the formation of the liver pre-metastatic } \\
\text { niche }\end{array}$ & $\begin{array}{l}\text { Up-regulate TGF- } \beta \text { expression and induce fibro- } \\
\text { nectin secretion }\end{array}$ & {$[116]$} \\
\hline Plectin & $\mathrm{hPaCa}-\mathrm{CM}$ & $\mathrm{hPaCa}$ cells & Induce migration, proliferation and invasion & Not mentioned & {$[117]$} \\
\hline $\begin{array}{l}\text { Tspan8/ } \\
106 / 49 d\end{array}$ & $\mathrm{rPaCa}-\mathrm{CM}$ & EC & $\begin{array}{l}\text { Induce proliferation, migration, sprouting and } \\
\text { progenitors maturation of EC }\end{array}$ & Induce VEGF-independent angiogenesis & [118] \\
\hline VEGF & $\mathrm{hPaCa}$ cells & $\mathrm{hPaCa}$ cells & Enhance tumor growth and angiogenesis & $\begin{array}{l}\text { Activate VEGF signal pathway to stimulate } \\
\text { angiogenesis and tumor growth }\end{array}$ & [119] \\
\hline ZIP4 & haPaCa-CM & $\mathrm{hPaCa}$ cells & $\begin{array}{l}\text { Increase proliferation, migration, and invasion of } \\
\text { non-metastatic } \mathrm{PaCa} \text { cells }\end{array}$ & Not mentioned & {$[120]$} \\
\hline miR-27a & $\mathrm{hPaCa}-\mathrm{CM}$ & HMVEC & Promote cell survival and growth & $\begin{array}{l}\text { Induce angiogenesis by inhibiting BTG2 } \\
\text { expression }\end{array}$ & {$[121]$} \\
\hline miR-222 & CM/Serum & $\mathrm{hPaCa}$ cells & Enhance proliferation and invasion & $\begin{array}{l}\text { Induce decrease, phosphorylation and } \\
\text { redistribution of p27 via PPP2R2A/Akt axis }\end{array}$ & [122] \\
\hline $\begin{array}{l}\operatorname{miR}-301 a- \\
3 p\end{array}$ & $\mathrm{hPaCa}-\mathrm{CM}$ & Macrophage & $\begin{array}{l}\text { Enhance migration and invasion, and induce } \\
\text { macrophage phenotype change }\end{array}$ & Activate PTEN/PI3K signaling pathway & [123] \\
\hline $\begin{array}{l}\operatorname{miR}-339- \\
5 p\end{array}$ & $\mathrm{mPaCa}-\mathrm{CM}$ & $\mathrm{mPaCa}$ cells & Enhance migration and invasion & $\begin{array}{l}\text { Decrease expression of zinc finger protein } \\
\text { ZNF689 }\end{array}$ & {$[124]$} \\
\hline $\begin{array}{l}\operatorname{miR}-501- \\
3 p\end{array}$ & Macrophage & $\mathrm{hPaCa}$ cells & Induce tumorigenesis and metastasis & $\begin{array}{l}\text { Decrease TGFBR3 levels and activate TGF- } \beta \\
\text { signaling }\end{array}$ & {$[125]$} \\
\hline $\begin{array}{l}\operatorname{miR}-1246 / \\
1290\end{array}$ & $\mathrm{hPaCa}-\mathrm{CM}$ & PSC & Promote PSC proliferation and pancreatic fibrosis & $\begin{array}{l}\text { Induce Akt/ERK activation and increase a-SMA } \\
\text { and procollagen type I C-peptide }\end{array}$ & {$[126]$} \\
\hline $\begin{array}{l}\text { mRNA- } \\
\text { hTERT }\end{array}$ & $\begin{array}{l}\mathrm{hPaCa} \\
\text { serum }\end{array}$ & PHFF & Induce proliferation and inhibit senescence & Enhance telomerase activity & {$[127]$} \\
\hline circ-IARS & $\mathrm{hPaCa}-\mathrm{CM}$ & EC/HUVEC & $\begin{array}{l}\text { Promote angiogenesis and metastasis by } \\
\text { enhancing endothelial monolayer permeability and } \\
\text { inducing HUVEC growth }\end{array}$ & $\begin{array}{l}\text { Down-regulate miR-122 and ZO-1, up-regulate } \\
\text { RhoA, RhoA-GTP, and F-actin as well as pro- } \\
\text { mote focal adhesion }\end{array}$ & [128] \\
\hline circ-PDE8A & $\begin{array}{l}\mathrm{hPaCa} \\
\text { serum }\end{array}$ & $\mathrm{hPaCa}$ cells & Promote invasive growth & Activate MACC/MET/ERK/Akt axis & [129] \\
\hline
\end{tabular}

demonstrated that $\mathrm{PaCaExos}$ reach the liver where they are uptaken by KCs, but also appear in the bone marrow and lung [132].

It has been shown that the knockout of $C D 151$ or TSPAN8 expression $\left(C D 151^{-/-}\right.$or $T_{S P A N 8^{-/-}}$, respectively) results in impaired metastasis of PaCa cells [111]. Remarkably, the re-introduction of regular PaCaExos into $\mathrm{CD}_{151^{-/-}}$or $\mathrm{TSPAN8}^{-/-}$cells can restore metastasis. Functional analysis has shown that CD151- and Tspan8-postive exosomes are able to (i) activate the expression of EMT-related genes in PaCa cells, (ii) induce ECM remodeling by activating stromal cells, and (iii) up- regulate the expression of pro-inflammatory factors in hematopoietic cells [111]. Furthermore, lymphangiogenesis is impaired and the hypersensitivity reaction is delayed in $\mathrm{TSPAN}^{-/-}$mice, while angiogenesis is severely impaired in both $C D 151^{-/-}$or TSPAN8 ${ }^{-/-}$mice. Still, metastasis of $\mathrm{PaCa}$ cells transplanted into either TSPA $N 8^{-/-}$or $\mathrm{TSPAN8}^{-/-} / \mathrm{CD} 151^{-/-}$mice is effectively inhibited, suggesting that host Tspan8 or CD151 can significantly affect tumor progression [112]. Totally, $\mathrm{PaCa}$ exosomal CD151 and Tspan8 may promote matrix degradation and reprogramming of the stroma and hematopoietic cells, which are essential steps for $\mathrm{PaCa}$ 
metastasis. CD44 variant isoform 6 (CD44v6) is highly expressed in $\mathrm{PaCa}$ cells and can be integrated into exosomes [133]. Upon uptake of PaCa-derived CD44v6positive exosomes by other $\mathrm{PaCa}$ cells, they activate $\mathrm{Wnt} / \beta$-Catenin signaling and up-regulate the expression of plasminogen activator inhibitor 1 (PAI-1), MMP, and tissue inhibitor of metalloproteases 1 (TIM-1), thus enhancing $\mathrm{PaCa}$ cell migration and metastatsis [110]. Since CD44v6 can promote TSPAN8 expression at the transcriptional level, $C D 44 v 6$ gene silencing effectively attenuates Tspan8-induced PaCa cell metastasis [134, 135]. Similarly, Jung and colleagues have observed that $C D 44 v 6$ gene knockout $\left(C D 44 v 6^{-1-}\right)$ severely impairs $\mathrm{PaCa}$ cell metastasis. Co-treatment of $\mathrm{CD} 44 \mathrm{v}^{-/-}$cells with soluble matrix (SM), produced by regular $\mathrm{PaCa}$ cells and PaCa-derived CD44v6-positive exosomes, can effectively restore the metastatic pattern of these cells, suggesting that $\mathrm{PaCa}$ may form a (pre-)metastatic niche microenvironment in distal metastasized organs by synergized effects derived of produced exosomes and other factors [136].

Myoferlin (MYOF) plays a crucial role in cell migration and invasion, as well as cell membrane endocytosis and vesicle transportation [137, 138]. It has been reported that MYOF can promote the migration and invasion of $\mathrm{PaCa}$ cells by regulating the mitochondrial structure and energy production [139, 140]. In $\mathrm{PaCa}$ cells, MYOF mediates the inclusion of VEGF into exosomes to promote tumor growth and angiogenesis. Accordingly, knockdown of MYOF expression can largely inhibit the growth and proliferation of $\mathrm{PaCa}$ cells [119]. Inhibition of MYOF function is also capable of reducing the volume of exosomes produced by $\mathrm{PaCa}$ cells as well as decreasing the levels of exosomal Rab7a and CD63. Although these exosomes with smaller volume are uptaken by human ECs, they fail to promote EC proliferation and migration, which eventually leads to inhibition of angiogenesis [118]. LIN28 is a $25-\mathrm{kDa}$ RNA-binding protein that has been shown to promote $\mathrm{PaCa}$ growth and metastasis by inhibiting the biogenesis of a group of microRNAs, including let-7. The $\mathrm{NAD}(+)$-dependent histone deacetylase sirtuin 6 (SIRT6) is able to induce $\mathrm{PaCa}$ growth inhibition by reducing LIN28 in PaCa cells [141]. Liver metastasis studies using $\mathrm{PaCa}$ tumor-bearing mice have demonstrated that LIN28B-positive exosomes produced by $\mathrm{PaCa}$ cells may reach target cells and activate the LIN28B/let-7/HMGA2/PDGFB signaling axis to further promote $\mathrm{PaCa}$ metastasis after injection via caudal vein [115].

Claudin 7 (Cld7) is a key structural protein present in tight junctions that interconnect cells [142]. It has also been shown that Cld7 can be distributed beyond TJ sites. For instance, palmitoylated Cld7 (Palm-Cld7) is localized in glycolipid-enriched membrane microdomains
(GEMM) [113]. Cld7 in tight junction (TJ-Cld7) is shown to regulate the entry of related proteins into $\mathrm{PaCaExos}$ and affect the function of exosomes derived from CICs (CIC-Exos) by modulating the composition of exosomal transporters and lipid metabolites, while Palm-Cld7-positive exosomes have the capability of regulating cell migration [113]. Importantly, Kyuno and colleagues have found that murine pancreatic cancer initiating cells $(\mathrm{PaCICs})$ can produce Cld7-positive exosomes which are capable of inducing re-programming of non-metastatic cancer cells to further increase their invasiveness [113]. Another PaCa-derived Wnt5 $\beta$-positive exosomes have been reported to enter and activate the Wnt5 $\beta$ signaling in other cancer cells lines such as $\mathrm{PaCa}$, A549 and Caco-2, where they stimulate migration and proliferation. Wnt5 $\beta$ knockout and TSG101 silencing can both abrogate the exosomal Wnt5 $\beta$-dependent $\mathrm{PaCa}$ cell proliferation and migration [143]. Under normal physiological conditions, plectin is usually localized in the cytoplasm where it functions as a scaffolding protein. Plectin is expressed in $\mathrm{PaCa}$, but usually undetectable in non-PaCa tissues [144]. In PaCa cells, integrin $\beta 4$ mediates the transfer of overexpressed plectin into exosomes, eventually leading to the proliferation, migration, and invasion of these cells [117].

Zinc transporter ZIP4-positive exosomes, produced by highly metastatic $\mathrm{PaCa}$ cells, can stimulate the proliferation, migration, and invasion of non-metastatic $\mathrm{PaCa}$ cells [145]. Accordingly, exosomal ZIP4 from the serum of $\mathrm{PaCa}$ patients can be used as a diagnostic marker for cancer progression [145]. Compared with exosomes derived from human pancreatic ductal epithelial cells (HPDE), exposure of non-tumorigenic cells to PaCaExos potentially induces transformation as well as tumorigenesis in vivo of non-malignant cells [120]. Functional analysis have indicated that PaCaExos are capable of inducing random gene mutations in recipient cells, while only certain cell populations with PaCaExo-induced mutations can undergo transformation and, eventually, become tumors. Considering the stochastic nature of mutations, the mechanism of PaCaExo-induced tumorigenesis in transformed cells may differ from each other [120]. Specifically, it has been reported that mutated DNA segments from KRAS, CDKN2A, P53, and SMAD4 can be internalized into PaCaExos. Thus, these exosomes may effectively promote the transformation of normal cells as well as subsequent tumor formation [146].

\section{PaCa exosomal nucleic acids}

It has been shown that miR-27a is overexpressed in cancer tissues from $\mathrm{PaCa}$ patients as well as $\mathrm{PaCa}$ cell lines [147]. PaCa-derived exosomes containing miR-27a can induce proliferation, invasion and angiogenesis in human 
microvascular endothelial cells (HMVECs) by suppressing B-cell translocation gene 2 (BTG2), which promotes $\mathrm{PaCa}$ cell survival and growth [121]. In contrast, in vivo studies using $\mathrm{PaCa}$ animal models have demonstrated miR-339-5p can inhibit cell invasion and migration by down-regulating the expression the zinc finger protein ZNF689. MiR-339-5p levels are significantly reduced in exosomes from highly metastatic PaCa cells. Accordingly, the exogenous introduction of miR-339-5p can effectively inhibit $\mathrm{PaCa}$ migration and invasion [124]. MiR-222 is overexpressed in highly invasive PaCa cells, where it is assimilated into exosomes. Upon uptake by poorly invasive $\mathrm{PaCa}$ cells, exosomal miR-222 is then released to further decrease the expression, phosphorylation, and nuclear exit of p27 via the PPP2R2A/Akt axis, which ultimately promotes the proliferation and invasion of respective cancer cells [122]. Moreover, abnormal ECM accumulation and blood vessel depletion in the TME can cause high desmoplasia and extreme hypoxia in $\mathrm{PaCa}$ tissues, which in turn stimulates cancer cells to ensure their survival by offsetting the hypoxic/ischemic environment via compensatory metabolic mechanisms that promote $\mathrm{PaCa}$ progression and apoptosis resistance [148]. The hypoxic environment inside the tumor, which is caused by rapid cell growth, can stimulate the production exosomal miR-301a-3p in PaCa cells [123]. After being acquired by other $\mathrm{PaCa}$ cells, miR-301a-3p-positive $\mathrm{PaCaExos}$ can promote the metastatic ability and invasiveness of these cancer cells. Upon uptake by macrophages, miR-301a-3p can also induce HIF $1 \alpha / 2 \alpha-$ dependent M2 phenotype transformation due to the activation of PTEN/PI3K signaling cascade [123]. Hypoxia has been shown to stimulate $\mathrm{PaCa}$ cells to generate more of small-volume exosomes via HIF1 $\alpha$, which increases the survival, proliferation, and metastasis of $\mathrm{PaCa}$ cells [149]. Additionally, exosomal miR-1246 has been found in the serum from patients with breast and prostate cancers [150, 151]. High levels of miR-1246 have been associated with GEM-resistance in $\mathrm{PaCa}$ cells, which can promote $\mathrm{PaCa}$ metastasis, invasion, cancer stemness, and angiogenesis due to the inhibition of CCNG2 expression [152]. However, it still remains unclear whether miR-1246 can enter exosomes to affect the chemoresistance in pancreatic cancer.

Besides the above distinct miRNAs, cancer tissues originated from $\mathrm{PaCa}$ patients have presented high levels of circular RNA IARS (circ-IARS) [128]. Exosomal circIARS produced by $\mathrm{PaCa}$ cells can promote cancer metastasis by increasing endothelial monolayer permeability and activating HUVECs to enhance angiogenesis. Mechanistic analyses have revealed that circ-IARS-positive exosomes may contribute to tumor invasion by (i) down-regulating miR-122 and ZO-1, (ii) up-regulating RhoA, RhoA-GTP, and F-actin and (iii) promoting focal adhesion. The high expression of circ-IARS has been positively correlated with liver metastasis, vascular invasion, and tumor-node-metastasis (TNM) of PaCa [128]. $\mathrm{Li}$ and colleagues have verified that metastatic $\mathrm{PaCa}$ cells in the liver present high levels of circular RNA PDE8A (circ-PDE8A). Serum circ-PDE8A-positive exosomes can induce invasive growth of $\mathrm{PaCa}$ cells by counteracting with miR-338 to activate the MACC/MET/ERK/Akt signaling axis [129]. Therefore, exosomal circ-PDE8A may be considered as a putative marker to predict $\mathrm{PaCa}$ metastatic progression. Additionally, exosomes from the serum of $\mathrm{PaCa}$ patients may also contain human telomerase reverse transcriptase (hTERT) mRNA [127]. PaCa-derived exosomes that are $h T E R T$ mRNA-positive can induce the transformation of non-malignant pancreatic fibroblasts (PF) into cells with high telomerase activity, thus stimulating cell proliferation and delaying aging [127].

\section{Exosomes produced by other cells and $\mathrm{PaCa}$ metastasis CAFs}

Cancer-associated fibroblasts (CAFs) that comprise main constituent cells of $\mathrm{PaCa}$ are essential for establishing the TME [153]. In TME, CAFs are able to regulate various behaviors and characteristics of $\mathrm{PaCa}$ cells, including epithelial-mesenchymal transition (EMT), proliferation, migration, invasion, metabolic transformation, and chemotherapy resistance $[154,155]$. It has been shown that CAF-derived exosomes can reprogram the energy metabolism and up-regulate mitochondrial oxidation in $\mathrm{PaCa}$ cells, which induces glycolysis and glutaminedependent reductive carboxylation to provides amino acids, fatty acids, as well as tricarboxylic acid cycle (TAC) intermediates for PaCa cells that are nutritionally deficient, thereby promoting the survival and growth of these cancer cells [156]. CAF-derived exosomes induced by gemcitabine (GEM) can activate miR-146a and the Snail signaling cascade in $\mathrm{PaCa}$ cells, thus promoting survival, proliferation, and drug resistance [157]. Interestingly, extracellular vesicles (EVs) containing annexin A6/LDL receptor-related protein 1/thrombospondin 1 (ANXA6/LRP1/TSP1) are solely present in the serum from PaCa patients. ANXA6/LRP1/TSP1-positive EVs are only produced by CAFs from $\mathrm{PaCa}$ patients, which are essential for liver metastasis [158]. Nevertheless, further studies are required to validate whether the ANXA6/LRP1/TSP1 complex may enter exosomes to support the aggressiveness of PaCa.

\section{TAMs}

Tumor-associated macrophages (TAMs), a class of TME-infiltrating macrophages, are capable of promoting the radio/chemotherapy resistance, angiogenesis, migration, invasion and metastasis of tumor cells [159]. It has 
been demonstrated that TAM-producing exosomes can promote $\mathrm{PaCa}$ metastasis and progression. For instance, exosomal miR-501-3p derived from M2 macrophages is able to inhibit TGFBR3 expression and then activate TGF- $\beta$ signaling, therefore inducing the formation and metastasis of $\mathrm{PaCa}$ xenografts in nude mice [125]. Analysis of clinical $\mathrm{PaCa}$ tissue specimens has indicated that miR-501-3p is also highly expressed in $\mathrm{PaCa}$ tissues. Exosomes produced by different types of $\mathrm{PaCa}$ cells (AsPC-1, BxPC-3, Panc-1, and MiaPaCa-2) contain distinct membrane proteins and lipid components that may affect the communication between $\mathrm{PaCa}$ cells and TAMs. For instance, exosomes produced by the ascitesderived human PDAC cell line AsPC-1 (AsPC-1-Exos) contain a large amount of ICAM-1 and arachidonic acid (AA). Since ICAM-1 can recognize and bind to CD11c on the surface of THP-1-derived macrophages (TDMs), AsPC-1-Exos can be uptaken rapidly by TDMs. The hydrolysis of AA in AsPC-1-Exos, catalyzed by phospholipase A2, has been shown to effectively reduce the fusion of AsPC-1-Exos with TDMs [114]. Treating nonpolarized M0 macrophages with AsPC-1-Exos can induce M0 macrophages to transition into immunosuppressive M2 macrophages. Moreover, AsPC-1-Exos can simulate TDMs to secrete a subset of cytokines, such as VEGF, MCP-1, IL-6, IL-1 $\beta$, MMP-9, and TNF- $\alpha$, thereby promoting the growth and progression of $\mathrm{PaCa}$ [114].

\section{CICs}

Cancer initiating cells (CICs) play a major role in the initiation of cancer cell migration and metastasis [160]. $\mathrm{PaCa}$-related CICs (PaCICs) can induce tumor stroma reorganization, stimulate angiogenesis, and promote hematopoietic cells to generate immunosuppressive cells via the production of exosomes (PaCIC-Exos), which eventually create a (pre-)metastatic niche in the distal metastatic organ [161, 162]. PaCIC-Exos can transfer certain characteristics of CICs to non-CICs, therefore inducing their reprogramming and promoting transformation characteristics such as anchorage-independent growth, apoptosis resistance, migration, and invasion, until they are phenotypically modified into CICs [163, 164]. In addition, PaCIC-Exos can be uptaken by non$\mathrm{CICs}$ and then increase the levels of p-Akt, Bcl-2, Bcl$\mathrm{X}_{\mathrm{L}}$, and MDR1, which potentially leads into the induction of metastatic growth, cisplatin resistance, EMT, migration, and invasion. Intravenous injection of Tspan8 antibody (CO029) has been shown to properly inhibit the drug resistance of non-CICs induced by CICs via exosomes [165], suggesting its use as a potential therapeutic target for $\mathrm{PaCa}$.

In PaCa cells, the expression of Tspan8 and other CIC marker proteins, such as integrin $\alpha 6 \beta 1$, CD104, EpCAM, CXCR4, and CD44v6, are mutually regulated. It has been demonstrated that knockdown of CD44v6 expression is capable of decreasing the invasiveness of PaCICs [165]. In contrast, CD151-positive exosomes produced by CICs can induce EMT and migration of $\mathrm{PaCa}$ cells [111]. CIC-produced Cld7-positive exosomes exhibit some activity to promote non-metastatic $\mathrm{PaCa}$ dissemination and metastatic growth, by increasing cell migration, invasion, and angiogenesis. Still, Cld7-positive exosomes do not have an apparent impact in apoptotic resistance, proliferation and EMT of tumor cells [166]. Functional studies have demonstrated that CIC-Exos can rescue the defects caused by Cld7 loss in $C L D 7^{\prime-} \mathrm{PaCa}$ cells, by activating integrin signaling pathway, proteases (such as uPA) and lymphangiogenic receptor (for instance, VEGF R3). Interestingly, the ability of CIC-Exos to promote tumor progression by activating receptor tyrosine kinase (RTK) can be blocked by the RTK inhibitor Sunitinib, indicating that RTK inhibition could be serves as a therapeutic approach in $\mathrm{PaCa}$ [166]. Furthermore, incubation of rat $\mathrm{PaCa}$ cells with Tspan8-positive exosomes carrying Cld7-specific miRNA may cause CLD7 gene silencing in vitro. Tspan 8 can significantly enhance the targeting of exosomal Cld7-related miRNAs to $\mathrm{PaCa}$ sites, leading to decreased $\mathrm{Cld} 7$ levels and further reduction on the expression of other CIC markers and Notch1, which suppress tumor cell growth, motility, and invasion [167]. Therefore, these modified exosomes may effectively load and carry nucleic acid fragments to tumor sites and help inhibit tumor progression.

\section{PSCS}

Pancreatic stellate cells (PSCs) play crucial roles in chronic pancreatitis and pancreatic fibrosis [72]. These cells are capable of interacting with tumor and surrounding stromal cells (such as immune and endothelial cells) to respectively promote cell growth and distant metastasis [168]. Exosomes produced by PSCs can stimulate $\mathrm{PaCa}$ cells to express a number of chemokines, including CCL20, CXCL1/2, PDZK1IP1, SAA1/2, SMCR7L, and ZNF619, which in turn promote the proliferation and migration of $\mathrm{PaCa}$ cells [169]. PaCa cell lines including Panc-1 and SUIT-2 can produce miR1246 and miR-1290-positive exosomes to induce cell proliferation and migration of PSCs by up-regulating the expression of $\alpha$-smooth muscle actin ( $\alpha$-SMA/ACTA2), increasing procollagen type I C-peptide production, and activating ERK/Akt signaling cascades [126]. Activated PSCs subsequently produce exosomes containing CD9, CCN2 and miR-21, which exacerbate tumor tissue fibrosis by stimulating other PSCs to secret and deposit more collagen [39]. Thus, PSCs communicate with $\mathrm{PaCa}$ cells via exosomes in the TME, which is essential for $\mathrm{PaCa}$ progression. 


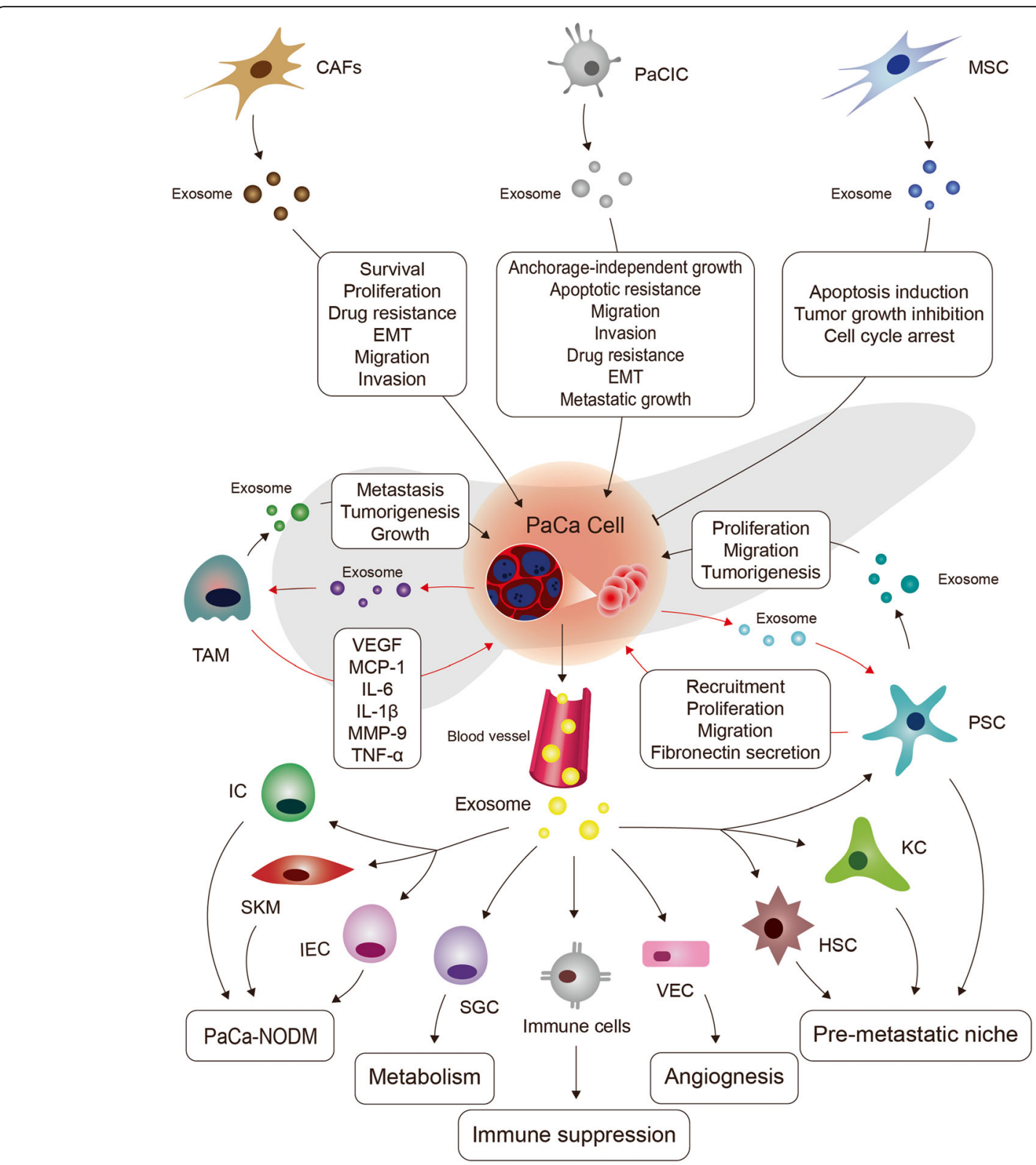

Fig. 3 Crosstalk between PaCa cells and PaCa-related cells. PaCa cells can interact with a variety of PaCa-related cells to fulfill their metastatic progress. On one hand, PaCa-related cells (CAFs, TAMs, PSCs, and PaCaCICs) generate exosomes that can promote PaCa cell survival, proliferation, apoptotic resistance, drug resistance, EMT, migration and metastatic invasion. Notably, MSCs can produce exosomes that induce apoptosis, cell cycle arrest and growth inhibition in PaCa cells. On the other hand, PaCa cells can also produce exosomes to stimulate various related cells to secrete various cytokines or exosomes, which may create a facilitating tumor microenvironment for their own survival and metastasis. Specifically, PaCa-derived exosomes can stimulate TAMs to produce many cytokines, including VEGF, which in turn can induce a variety of metastatic characterization changes such as EMT in PaCa cells. PaCa -derived exosomes can recruit and stimulate PSCs to proliferate, migrate and secrete more fibronectin, thereby creating a metastasis microenvironment. PaCa cells may additionally produce exosomes to deregulate the body metabolism, impairing the functions of ICS, IECS, SGCs and SKMs. PaCa-derived exosomes can stimulate the proliferation and migration of VECs, thus forming new blood vessels, inducing KC and HSC activation to form a distant metastasis microenvironment in the liver, as well as targeting immune cells (including DCs) to promote immunosuppression

\section{Conclusion and perspectives}

Our current study discusses the roles of exosomes towards $\mathrm{PaCa}$ initiation and metastatic progression. To date, most of the published studies have started to uncover the notion that exosomes exert their biological function in definition of $\mathrm{PaCa}$ pathogenesis and may serve as culprits behind $\mathrm{PaCa}$ metastasis. On one hand, exosomes mediate pancreas precancerous diseases caused by various conditions, including diabetes, inflammation and viral infections, which can promote and 
accelerate their transformation into $\mathrm{PaCa}$. This suggests that targeting relevant exosomes may help preventing $\mathrm{PaCa}$ from precancerous stages, restoring the abnormal pancreas to a healthy state, and developing earlier diagnostic methods. On the other hand, key nodal studies, such as the identification of exosomes and their detailed molecular mechanisms involved in ADM or AFDL are still limited and may need to be strengthened and further explored. During recent years, it has been seminal to elucidate whether some newly discovered important regulatory factors, such as $\mathrm{m}$ (6) A modified regulatory factors, PDL-1, and non-coding RNAs, participate in the development of $\mathrm{PaCa}$ through exosomes-mediated signaling cascades. More importantly, a variety of $\mathrm{PaCa}-$ related cells, including $\mathrm{PaCaCICs}$, CAFs, PSCs, MSCs, DCs, HSCs, TAMs, and PaCa-NODM-related cells, can crosstalk with $\mathrm{PaCa}$ cells through exosomes (Fig. 3). This intercommunication can not only establish a facilitating microenvironment for $\mathrm{PaCa}$ metastasis by generating exosomes around the tumor or in the distant organs, but can also render particular properties to $\mathrm{PaCa}$ cells such as apoptosis resistance, migration, EMT, and ultimately metastasis.

It is worth noting that, along with the occurrence and metastasis of $\mathrm{PaCa}$, the human body also drives some biological reactions, including immune response to limit $\mathrm{PaCa}$ progression, even though these antitumor effects may not be dominant. For instance, the abovementioned MSCs can produce some special exosomes after differentiation into various subgroups, which induce apoptosis, cycle arrest and growth inhibition of PaCa cells. In addition, studies have confirmed that these endogenous exosomes may carry various substances without causing an immune response in the body, suggesting their utilization as putative drug carriers [170]. As an example, it has been found that exosomes derived from macrophages may carry chemotherapeutic drugs (doxorubicin), which are toxic to $\mathrm{PaCa}$ cells [171]. Interestingly, exosomes generated by $\mathrm{PaCa}$ cells also contain some tumor suppressor components, which may exert anti-cancer activity by inducing apoptosis and inhibiting proliferation of related cancer cells [172]. These findings have revealed the potential therapeutic value of exosomes. Therefore, to exploit these favorable variables may contribute to the diagnosis and treatment of $\mathrm{PaCa}$ in the near future. Nevertheless, it must be said that studies focusing on PaCa-related exosomes are still under progression. Some technical limitations, such as an effective exosome delivery, high pure and bulk exosome preparation with standard protocol, and exosome target specificity, are the biggest challenges and still need to be properly considered before any diagnostic or therapeutic applications are established.

\section{Abbreviations}

ADM: Acinar-to-ductal metaplasia; AIP: Autoimmune pancreatitis; AP: Acute pancreatitis; APCs: Antigen presenting cells; AP-cirExos: Circulating exosomes from AP patients; CAFs: Cancer-associated fibroblasts; CD44v6: CD44 variant isoform 6; CICs: Cancer initiating cells; CIC-Exos: Exosomes derived from $\mathrm{ClCs}$; CTGF2/CCN2: Connective tissue growth factor 2; CP: Chronic pancreatitis; cirExos: Circulating exosomes; Cld7: Claudin 7; CVB3: Coxsackie virus B3; DM: Diabetes mellitus; ECM: Extracellular matrix; ECs: Epithelial cells; EMT: Epithelial-mesenchymal transition; ESCRT: Endosome sorting complex required for transport; FABP4: Fatty acid-binding protein 4;

GEM: Gemcitabine; HPAD: High palmitic acid diet; HUVECs: Human umbilical vein endothelial cells; IH: Intermittent hypoxia; ILs: Interleukins; IPMN: Intraductal papillary malignant neoplasm; ILVs: Intraluminal vesicles; MHC: Major histocompatibility complex; MIF: Migration inhibitory factor; miRNAs/miRs: microRNAs; MYOF: Myoferlin; MSCs: Mesenchymal stem cells; MVBs: Multivesicular bodies; OSA: Obstructive sleep apnea; PAAFExos: Pancreatitis-associated ascitic fluid; PaCa: Pancreatic cancer; PaClCs: Pancreatic cancer initiating cells; PaCaExos: Exosomes from PaCa cells; Palm-Cld7: Palmitoylated Cld7; PanINs: Pancreatic intraepithelial neoplasias; PDAC: Pancreatic ductal adenocarcinoma; PRKD-1: Protein kinase D1; PSCs: Pancreatic stellate cells; RTK: Receptor tyrosine kinase; SKM: Skeletal muscle; TAAs: Tumor-associated antigens; TJ-Cld7: Cld7 in tight junctions (TJ); TAMs: Tumor-associated macrophages; TME: Tumor microenvironment; TEMs: Tspan-enriched microdomains; TLRs: Toll-like receptors; T1DM: Type 1 DM; T2DM: Type 2 DM

\section{Acknowledgments}

Not applicable.

Ethical approval and consent to participate

Not applicable.

\section{Authors' contributions}

$X X Z$ and ZML designed the review. WS, YR, XXZ and ZML drafted the manuscript and prepared the tables and figures. All authors read and approved the final manuscript.

\section{Funding}

This work was partially supported by National Natural Science Foundation of China (31371425) and Liaoning Provincial Natural Science Foundation of China (20180551061, 20180551174).

\section{Availability of data and materials}

All data and information in this review can be found in the reference list.

\section{Consent for publication}

All authors consent to publication.

\section{Competing interests}

The authors declare no competing interests.

Received: 6 July 2020 Accepted: 25 August 2020

Published online: 02 September 2020

\section{References}

1. Bisht S, Feldmann G. Novel targets in pancreatic cancer therapy - current status and ongoing translational efforts. Oncol Res Treat. 2018;41:596-602.

2. Deplanque G, Demartines N. Pancreatic cancer: are more chemotherapy and surgery needed? Lancet. 2017;389:985-6.

3. Cameron JL, He J. Two thousand consecutive pancreaticoduodenectomies. J Am Coll Surg. 2015;220:530-6.

4. Seton-Rogers S. Tumorigenesis: pushing pancreatic cancer to take off. Nat Rev Cancer. 2012;12:739.

5. Wang $L$, Xie D, Wei D. Pancreatic acinar-to-ductal metaplasia and pancreatic cancer. Methods Mol Biol. 2019;1882:299-308.

6. Sawey ET, Johnson JA, Crawford HC. Matrix metalloproteinase 7 controls pancreatic acinar cell transdifferentiation by activating the notch signaling pathway. Proc Natl Acad Sci U S A. 2007;104:19327-32.

7. Wauters E, Sanchez-Arevalo Lobo VJ, Pinho AV, Mawson A, Herranz D, Wu J, Cowley MJ, Colvin EK, Njicop EN, Sutherland RL, et al. Sirtuin-1 regulates 
acinar-to-ductal metaplasia and supports cancer cell viability in pancreatic cancer. Cancer Res. 2013;73(7):2357-67.

8. Benitz S, Regel I, Reinhard T, Popp A, Schaffer I, Raulefs S, Kong B, Esposito I, Michalski CW, Kleeff J. Polycomb repressor complex 1 promotes gene silencing through H2AK119 mono-ubiquitination in acinar-to-ductal metaplasia and pancreatic cancer cells. Oncotarget. 2016;7:11424-33.

9. Basturk O, Hong SM, Wood LD, Adsay NV, Albores-Saavedra J, Biankin AV, Brosens LA, Fukushima N, Goggins M, Hruban RH, et al. A revised classification system and recommendations from the Baltimore consensus meeting for neoplastic precursor lesions in the pancreas. Am J Surg Pathol. 2015;39:1730-41.

10. Buscail L, Bournet B, Cordelier P. Role of oncogenic KRAS in the diagnosis, prognosis and treatment of pancreatic cancer. Nat Rev Gastroenterol Hepatol. 2020;17:153-68.

11. Tang B, Yang Y, Kang M, Wang Y, Wang Y, Bi Y, He S, Shimamoto F. m (6) A demethylase ALKBH5 inhibits pancreatic cancer tumorigenesis by decreasing WIF-1 RNA methylation and mediating Wnt signaling. Mol Cancer. 2020;19:3.

12. LV Y, Huang S. Role of non-coding RNA in pancreatic cancer. Oncol Lett. 2019;18:3963-73.

13. Thery C, Zitvogel L, Amigorena S. Exosomes: composition, biogenesis and function. Nat Rev Immunol. 2002;2:569-79.

14. Kalluri R. The biology and function of exosomes in cancer. J Clin Invest. 2016;126:1208-15.

15. Zhang W, Xia W, Lv Z, Ni C, Xin Y, Yang L. Liquid biopsy for cancer: circulating tumor cells, circulating free DNA or exosomes? Cell Physiol Biochem. 2017:41:755-68.

16. Wu H, Chen X, Ji J, Zhou R, Liu J, Ni W, Qu L, Ni H, Ni R, Bao B, et al. Progress of exosomes in the diagnosis and treatment of pancreatic cancer. Genet Test Mol Biomark. 2019;23:215-22.

17. Yan Y, Fu G, Ming L. Role of exosomes in pancreatic cancer. Oncol Lett. 2018;15:7479-88.

18. Zhao C, Gao F, Weng S, Liu Q. Pancreatic cancer and associated exosomes. Cancer Biomark. 2017;20:357-67.

19. Wang CC, Zhao YM, Wang HY, Zhao YP. New insight into the role of exosomes in pancreatic cancer. Ann Clin Lab Sci. 2019;49:385-92.

20. Guo XY, Xiao F, Li J, Zhou YN, Zhang WJ, Sun B, Wang G. Exosomes and pancreatic diseases: status, challenges, and hopes. Int J Biol Sci. 2019;15:1846-60.

21. Kowal J, Arras G, Colombo M, Jouve M, Morath JP, Primdal-Bengtson B, Dingli F, Loew D, Tkach M, Thery C. Proteomic comparison defines novel markers to characterize heterogeneous populations of extracellular vesicle subtypes. Proc Natl Acad Sci U S A. 2016;113:E968-77.

22. Andreu Z, Yanez-Mo M. Tetraspanins in extracellular vesicle formation and function. Front Immunol. 2014;5:442.

23. Perez-Hernandez D, Gutierrez-Vazquez C, Jorge I, Lopez-Martin S, Ursa A, Sanchez-Madrid F, Vazquez J, Yanez-Mo M. The intracellular interactome of tetraspanin-enriched microdomains reveals their function as sorting machineries toward exosomes. J Biol Chem. 2013;288:11649-61.

24. Colombo M, Raposo G, Thery C. Biogenesis, secretion, and intercellular interactions of exosomes and other extracellular vesicles. Annu Rev Cell Dev Biol. 2014;30:255-89.

25. Jalalian SH, Ramezani M, Jalalian SA, Abnous K, Taghdisi SM. Exosomes, new biomarkers in early cancer detection. Anal Biochem. 2019:571:1-13.

26. Bu H, He D, He X, Wang K. Exosomes: isolation, analysis, and applications in cancer detection and therapy. Chembiochem. 2019:20:451-61.

27. Huotari J, Helenius A. Endosome maturation. EMBO J. 2011;30:3481-500.

28. Ostrowski M, Carmo NB, Krumeich S, Fanget I, Raposo G, Savina A, Moita CF, Schauer K, Hume AN, Freitas RP, et al. Rab27a and Rab27b control different steps of the exosome secretion pathway. Nat Cell Biol. 2010;12:19-30 sup pp 11-3.

29. Pfeffer SR. Unsolved mysteries in membrane traffic. Annu Rev Biochem. 2007;76:629-45

30. Stuffers S, Sem Wegner C, Stenmark H, Brech A. Multivesicular endosome biogenesis in the absence of ESCRTs. Traffic. 2009;10:925-37.

31. Escola JM, Kleijmeer MJ, Stoorvogel W, Griffith JM, Yoshie O, Geuze HJ. Selective enrichment of tetraspan proteins on the internal vesicles of multivesicular endosomes and on exosomes secreted by human Blymphocytes. J Biol Chem. 1998;273:20121-7.

32. Trajkovic K, Hsu C, Chiantia S, Rajendran L, Wenzel D, Wieland F, Schwille P, Brugger B, Simons M. Ceramide triggers budding of exosome vesicles into multivesicular endosomes. Science. 2008;319:1244-7.
33. Jadli AS, Ballasy N, Edalat P, Patel VB. Inside (sight) of tiny communicator: exosome biogenesis, secretion, and uptake. Mol Cell Biochem. 2020;467:7794.

34. Davison L. Diabetes mellitus and pancreatitis--cause or effect? I Small Anim Pract. 2015;56:50-9.

35. Remmers N, Bailey JM, Mohr AM, Hollingsworth MA. Molecular pathology of early pancreatic cancer. Cancer Biomark. 2010;9:421-40.

36. Wolfgang $\mathrm{CL}$, Herman JM, Laheru DA, Klein AP, Erdek MA, Fishman EK, Hruban RH. Recent progress in pancreatic cancer. CA Cancer J Clin. 2013;63: $318-48$.

37. Cicenas J, Kvederaviciute K, Meskinyte I, Meskinyte-Kausiliene E, Skeberdyte A, Cicenas J. KRAS, TP53, CDKN2A, SMAD4, BRCA1, and BRCA2 mutations in pancreatic cancer. Cancers. 2017;9:42.

38. Cianciaruso C, Phelps EA, Pasquier M, Hamelin R, Demurtas D, Alibashe Ahmed M, Piemonti L, Hirosue S, Swartz MA, De Palma M, et al. Primary human and rat beta-cells release the intracellular autoantigens GAD65, IA-2, and proinsulin in exosomes together with cytokine-induced enhancers of immunity. Diabetes. 2017;66:460-73.

39. Charrier A, Chen R, Chen L, Kemper S, Hattori T, Takigawa M, Brigstock DR Connective tissue growth factor (CCN2) and microRNA-21 are components of a positive feedback loop in pancreatic stellate cells (PSC) during chronic pancreatitis and are exported in PSC-derived exosomes. J Cell Commun Signal. 2014;8:147-56.

40. Ertunc ME, Sikkeland J, Fenaroli F, Griffiths G, Daniels MP, Cao H, Saatcioglu F, Hotamisligil GS. Secretion of fatty acid binding protein aP2 from adipocytes through a nonclassical pathway in response to adipocyte lipase activity. J Lipid Res. 2015;56:423-34.

41. Wang N, Ma J, Ren Y, Xiang S, Jia R. Secreted klotho from exosomes alleviates inflammation and apoptosis in acute pancreatitis. Am J Transl Res. 2019:11:3375-83.

42. Deng ZB, Poliakov A, Hardy RW, Clements R, Liu C, Liu Y, Wang J, Xiang X, Zhang $S$, Zhuang $X$, et al. Adipose tissue exosome-like vesicles mediate activation of macrophage-induced insulin resistance. Diabetes. 2009;58: 2498-505.

43. Lu M, Huang B, Hanash SM, Onuchic JN, Ben-Jacob E. Modeling putative therapeutic implications of exosome exchange between tumor and immune cells. Proc Natl Acad Sci U S A. 2014;111:E4165-74.

44. Gehrmann U, Naslund TI, Hiltbrunner S, Larssen P, Gabrielsson S. Harnessing the exosome-induced immune response for cancer immunotherapy. Semin Cancer Biol. 2014;28:58-67.

45. Capello M, Vykoukal JV, Katayama H, Bantis LE, Wang H, Kundnani DL, Aguilar-Bonavides C, Aguilar M, Tripathi SC, Dhillon DS, et al. Exosomes harbor B cell targets in pancreatic adenocarcinoma and exert decoy function against complement-mediated cytotoxicity. Nat Commun. 2019;10: 254.

46. Jalabert A, Vial G, Guay C, Wiklander OP, Nordin JZ, Aswad H, Forterre A, Meugnier E, Pesenti S, Regazzi R, et al. Exosome-like vesicles released from lipid-induced insulin-resistant muscles modulate gene expression and proliferation of beta recipient cells in mice. Diabetologia. 2016;59:1049-58,

47. Garcia-Contreras M, Shah SH, Tamayo A, Robbins PD, Golberg RB, Mendez AJ, Ricordi C. Plasma-derived exosome characterization reveals a distinct microRNA signature in long duration type 1 diabetes. Sci Rep. 2017;7:5998.

48. Eissa S, Matboli M, Bekhet MM. Clinical verification of a novel urinary microRNA panal: 133b, -342 and -30 as biomarkers for diabetic nephropathy identified by bioinformatics analysis. Biomed Pharmacother. 2016;83:92-9.

49. Tsukita S, Yamada T, Takahashi K, Munakata Y, Hosaka S, Takahashi H, Gao J, Shirai Y, Kodama S, Asai Y, et al. MicroRNAs 106b and 222 improve hyperglycemia in a mouse model of insulin-deficient diabetes via pancreatic beta-cell proliferation. EBioMedicine. 2017;15:163-72.

50. Guay C, Kruit JK, Rome S, Menoud V, Mulder NL, Jurdzinski A, Mancarella F, Sebastiani G, Donda A, Gonzalez BJ, et al. Lymphocyte-derived exosomal microRNAs promote pancreatic beta cell death and may contribute to type 1 diabetes development. Cell Metab. 2019;29:348-61 e346.

51. Guay C, Menoud V, Rome S, Regazzi R. Horizontal transfer of exosomal microRNAs transduce apoptotic signals between pancreatic beta-cells. Cell Commun Signal. 2015;13:17.

52. Ying $W$, Riopel $M$, Bandyopadhyay $G$, Dong $Y$, Birmingham $A$, Seo JB, Ofrecio JM, Wollam J, Hernandez-Carretero A, Fu W, et al. Adipose tissue macrophage-derived exosomal miRNAs can modulate in vivo and in vitro insulin sensitivity. Cell. 2017;171:372-84 e312. 
53. Safwat A, Sabry D, Ragiae A, Amer E, Mahmoud RH, Shamardan RM. Adipose mesenchymal stem cells-derived exosomes attenuate retina degeneration of streptozotocin-induced diabetes in rabbits. J Circ Biomark. 2018;7:1849454418807827.

54. Jin J, Shi Y, Gong J, Zhao L, Li Y, He Q, Huang H. Exosome secreted from adipose-derived stem cells attenuates diabetic nephropathy by promoting autophagy flux and inhibiting apoptosis in podocyte. Stem Cell Res Ther. 2019:10:95.

55. Zhou M, Chen J, Zhou L, Chen W, Ding G, Cao L. Pancreatic cancer derived exosomes regulate the expression of TLR4 in dendritic cells via miR-203. Cell Immunol. 2014;292:65-9.

56. Ding G, Zhou L, Qian Y, Fu M, Chen J, Chen J, Xiang J, Wu Z, Jiang G, Cao L. Pancreatic cancer-derived exosomes transfer miRNAs to dendritic cells and inhibit RFXAP expression via miR-212-3p. Oncotarget. 2015;6:29877-88.

57. Saravanan PB, Vasu S, Yoshimatsu G, Darden CM, Wang X, Gu J, Lawrence MC, Naziruddin B. Differential expression and release of exosomal miRNAs by human islets under inflammatory and hypoxic stress. Diabetologia. 2019; 62:1901-14.

58. Fu Q, Jiang $H$, Wang Z, Wang X, Chen H, Shen Z, Xiao L, Guo X, Yang T. Injury factors alter miRNAs profiles of exosomes derived from islets and circulation. Aging. 2018;10:3986-99.

59. Basso D, Gnatta E, Padoan A, Fogar P, Furlanello S, Aita A, Bozzato D, Zambon CF, Arrigoni G, Frasson C, et al. PDAC-derived exosomes enrich the microenvironment in MDSCs in a SMAD4-dependent manner through a new calcium related axis. Oncotarget. 2017:8:84928-44.

60. Chen C, Zong S, Liu Y, Wang Z, Zhang Y, Chen B, Cui Y. Profiling of exosomal biomarkers for accurate cancer identification: combining DNAPAINT with machine- learning-based classification. Small. 2019;15:e1901014.

61. Lowenfels AB, Maisonneuve P, Cavallini G, Ammann RW, Lankisch PG, Andersen JR, Dimagno EP, Andren-Sandberg A, Domellof L. Pancreatitis and the risk of pancreatic cancer. International Pancreatitis Study Group. N Engl J Med. 1993;328:1433-7.

62. Nojgaard C, Becker U, Matzen P, Andersen JR, Holst C, Bendtsen F. Progression from acute to chronic pancreatitis: prognostic factors, mortality, and natural course. Pancreas. 2011;40:1195-200.

63. Brodovicz KG, Kou TD, Alexander CM, O'Neill EA, Engel SS, Girman CJ, Goldstein BJ. Impact of diabetes duration and chronic pancreatitis on the association between type 2 diabetes and pancreatic cancer risk. Diabetes Obes Metab. 2012;14:1123-8

64. Raimondi S, Lowenfels AB, Morselli-Labate AM, Maisonneuve P, Pezzilli R. Pancreatic cancer in chronic pancreatitis; aetiology, incidence, and early detection. Best Pract Res Clin Gastroenterol. 2010;24:349-58.

65. Ghazale A, Chari S. Is autoimmune pancreatitis a risk factor for pancreatic cancer? Pancreas. 2007;35:376.

66. Bonjoch L, Casas V, Carrascal M, Closa D. Involvement of exosomes in lung inflammation associated with experimental acute pancreatitis. J Pathol. 2016:240:235-45.

67. Wu XB, Sun HY, Luo ZL, Cheng L, Duan XM, Ren JD. Plasma-derived exosomes contribute to pancreatitis-associated lung injury by triggering NLRP3-dependent pyroptosis in alveolar macrophages. Biochim Biophys Acta Mol basis Dis. 1866:2020:165685

68. Jimenez-Alesanco A, Marcuello M, Pastor-Jimenez M, Lopez-Puerto L, Bonjoch L, Gironella M, Carrascal M, Abian J, de-Madaria E, Closa D. Acute pancreatitis promotes the generation of two different exosome populations. Sci Rep. 2019;9:19887.

69. Wolf I, Laitman Y, Rubinek T, Abramovitz L, Novikov I, Beeri R, Kuro OM, Koeffler HP, Catane R, Freedman LS, et al. Functional variant of KLOTHO: a breast cancer risk modifier among BRCA1 mutation carriers of Ashkenazi origin. Oncogene. 2010;29:26-33.

70. Poh W, Wong W, Ong H, Aung MO, Lim SG, Chua BT, Ho HK. Klotho-beta overexpression as a novel target for suppressing proliferation and fibroblast growth factor receptor-4 signaling in hepatocellular carcinoma. Mol Cancer. 2012;11:14.

71. Charrier A, Brigstock DR. Regulation of pancreatic function by connective tissue growth factor (CTGF, CCN2). Cytokine Growth Factor Rev. 2013;24:59-68.

72. Jin G, Hong W, Guo Y, Bai Y, Chen B. Molecular mechanism of pancreatic stellate cells activation in chronic pancreatitis and pancreatic cancer. J Cancer. 2020;11:1505-15.

73. Apte M, Pirola R, Wilson J. The fibrosis of chronic pancreatitis: new insights into the role of pancreatic stellate cells. Antioxid Redox Signal. 2011;15: 2711-22.
74. Nagathihalli NS, Castellanos JA, VanSaun MN, Dai X, Ambrose M, Guo Q, Xiong Y, Merchant NB. Pancreatic stellate cell secreted IL-6 stimulates STAT3 dependent invasiveness of pancreatic intraepithelial neoplasia and cancer cells. Oncotarget. 2016;7:65982-92.

75. Erkan M. The role of pancreatic stellate cells in pancreatic cancer. Pancreatology. 2013;13:106-9.

76. Zhao Y, Wang H, Lu M, Qiao X, Sun B, Zhang W, Xue D. Pancreatic acinar cells employ miRNAs as mediators of intercellular communication to participate in the regulation of pancreatitis-associated macrophage activation. Mediat Inflamm. 2016;2016:6340457.

77. El-Sayed R, El-Karaksy H. Acute pancreatitis complicating acute hepatitis A virus infection. Arab J Gastroenterol. 2012;13:184-5.

78. Qi CF, Kim YS, Xiang S, Abdullaev Z, Torrey TA, Janz S, Kovalchuk AL, Sun J, Chen D, Cho WC, et al. Characterization of ARF-BP1/HUWE1 interactions with CTCF, MYC, ARF and p53 in MYC-driven B cell neoplasms. Int J Mol Sci. 2012;13:6204-19.

79. Hammami MB, Aboushaar R, Musmar A, Hammami S. Epstein-Barr virusassociated acute pancreatitis. BMJ Case Rep. 2019;12:e231744.

80. Liu X, Clemens DL, Grunkemeyer JA, Price JD, O'Connell K, Chapman NM, Storz P, Wen H, Cox JL, Reid WL, et al. Mucin-1 is required for Coxsackie virus B3-induced inflammation in pancreatitis. Sci Rep. 2019;9:10656.

81. Inal JM, Jorfi S. Coxsackievirus B transmission and possible new roles for extracellular vesicles. Biochem Soc Trans. 2013;41:299-302.

82. Batabyal P, Vander Hoorn S, Christophi C, Nikfarjam M. Association of diabetes mellitus and pancreatic adenocarcinoma: a meta-analysis of 88 studies. Ann Surg Oncol. 2014;21:2453-62

83. Yao ZY, Chen WB, Shao SS, Ma SZ, Yang CB, Li MZ, Zhao JJ, Gao L. Role of exosome-associated microRNA in diagnostic and therapeutic applications to metabolic disorders. J Zhejiang Univ Sci B. 2018;19:183-98.

84. Sharma A, Smyrk TC, Levy MJ, Topazian MA, Chari ST. Fasting blood glucose levels provide estimate of duration and progression of pancreatic cancer before diagnosis. Gastroenterology. 2018;155:490-500 e492.

85. Kong Q, Guo X, Guo Z, Su T. Urinary exosome miR-424 and miR-218 as biomarkers for type 1 diabetes in children. Clin Lab. 2019;65:937-46.

86. Ge Q, Xie XX, Xiao X, Li X. Exosome-like vesicles as new mediators and therapeutic targets for treating insulin resistance and beta-cell mass failure in type 2 diabetes mellitus. J Diabetes Res. 2019;2019:3256060.

87. Delong T, Wiles TA, Baker RL, Bradley B, Barbour G, Reisdorph R, Armstrong M, Powell RL, Reisdorph N, Kumar N, et al. Pathogenic CD4 T cells in type 1 diabetes recognize epitopes formed by peptide fusion. Science. 2016;351:711-4.

88. Bashratyan R, Sheng H, Regn D, Rahman MJ, Dai YD. Insulinoma-released exosomes activate autoreactive marginal zone-like B cells that expand endogenously in prediabetic NOD mice. Eur J Immunol. 2013;43:2588-97.

89. Uysal KT, Scheja L, Wiesbrock SM, Bonner-Weir S, Hotamisligil GS. Improved glucose and lipid metabolism in genetically obese mice lacking aP2. Endocrinology. 2000;141:3388-96.

90. Poy MN, Eliasson L, Krutzfeldt J, Kuwajima S, Ma X, Macdonald PE, Pfeffer S, Tuschl T, Rajewsky N, Rorsman P, et al. A pancreatic islet-specific microRNA regulates insulin secretion. Nature. 2004;432:226-30.

91. Poy MN, Hausser J, Trajkovski M, Braun M, Collins S, Rorsman P, Zavolan M, Stoffel M. miR-375 maintains normal pancreatic alpha- and beta-cell mass. Proc Natl Acad Sci U S A. 2009;106:5813-8.

92. Kloosterman WP, Lagendijk AK, Ketting RF, Moulton JD, Plasterk RH. Targeted inhibition of miRNA maturation with morpholinos reveals a role for miR-375 in pancreatic islet development. PLoS Biol. 2007:5:e203.

93. Belgardt BF, Ahmed K, Spranger M, Latreille M, Denzler R, Kondratiuk N, von Meyenn F, Villena FN, Herrmanns K, Bosco D, et al. The microRNA-200 family regulates pancreatic beta cell survival in type 2 diabetes. Nat Med. 2015;21: 619-27.

94. Whiteside TL. Exosomes in cancer: another mechanism of tumor-induced immune suppression. Adv Exp Med Biol. 2017;1036:81-9.

95. Tucci M, Passarelli A, Mannavola F, Felici C, Stucci LS, Cives M, Silvestris F. Immune system evasion as Hallmark of melanoma progression: the role of dendritic cells. Front Oncol. 2019;9:1148.

96. Zech D, Rana S, Buchler MW, Zoller M. Tumor-exosomes and leukocyte activation: an ambivalent crosstalk. Cell Commun Signal. 2012;10:37.

97. Ansari D, Friess H, Bauden M, Samnegard J, Andersson R. Pancreatic cancer: disease dynamics, tumor biology and the role of the microenvironment. Oncotarget. 2018;9:6644-51.

98. Stromnes IM, Greenberg PD, Hingorani SR. Molecular pathways: myeloid complicity in cancer. Clin Cancer Res. 2014;20:5157-70. 
99. Stromnes IM, Brockenbrough JS, Izeradjene K, Carlson MA, Cuevas C, Simmons RM, Greenberg PD, Hingorani SR. Targeted depletion of an MDSC subset unmasks pancreatic ductal adenocarcinoma to adaptive immunity. Gut. 2014;63:1769-81.

100. Ryan DP, Hong TS, Bardeesy N. Pancreatic adenocarcinoma. N Engl J Med. 2014:371:2140-1.

101. Sanchez GV, Weinstein SJ, Stolzenberg-Solomon RZ. Is dietary fat, vitamin D, or folate associated with pancreatic cancer? Mol Carcinog. 2012;51:119-27.

102. Dawson DW, Hertzer K, Moro A, Donald G, Chang HH, Go VL, Pandol SJ, Lugea A, Gukovskaya AS, Li G, et al. High-fat, high-calorie diet promotes early pancreatic neoplasia in the conditional KrasG12D mouse model. Cancer Prev Res (Phila). 2013;6:1064-73.

103. Xue L, Yang K, Newmark H, Leung D, Lipkin M. Epithelial cell hyperproliferation induced in the exocrine pancreas of mice by a westernstyle diet. J Natl Cancer Inst. 1996;88:1586-90.

104. Forterre A, Jalabert A, Chikh K, Pesenti S, Euthine V, Granjon A, Errazuriz E, Lefai E, Vidal H, Rome S. Myotube-derived exosomal miRNAs downregulate Sirtuin1 in myoblasts during muscle cell differentiation. Cell Cycle. 2014;13: 78-89.

105. Aswad H, Forterre A, Wiklander OP, Vial G, Danty-Berger E, Jalabert A, Lamaziere A, Meugnier E, Pesenti S, Ott C, et al. Exosomes participate in the alteration of muscle homeostasis during lipid-induced insulin resistance in mice. Diabetologia. 2014;57:2155-64.

106. Marshall NS, Wong KK, Cullen SR, Knuiman MW, Grunstein RR. Sleep apnea and 20-year follow-up for all-cause mortality, stroke, and cancer incidence and mortality in the Busselton health study cohort. J Clin Sleep Med. 2014; 10:355-62.

107. Almendros I, Montserrat JM, Ramirez J, Torres M, Duran-Cantolla J, Navajas $D$, Farre R. Intermittent hypoxia enhances cancer progression in a mouse model of sleep apnoea. Eur Respir J. 2012;39:215-7.

108. Almendros I, Khalyfa A, Trzepizur W, Gileles-Hillel A, Huang L, Akbarpour M, Andrade J, Farre R, Gozal D. Tumor cell malignant properties are enhanced by circulating exosomes in sleep apnea. Chest. 2016;150:1030-41.

109. Filipazzi P, Burdek M, Villa A, Rivoltini L, Huber V. Recent advances on the role of tumor exosomes in immunosuppression and disease progression. Semin Cancer Biol. 2012;22:342-9.

110. Wang Z, von Au A, Schnolzer M, Hackert T, Zoller M. CD44v6-competent tumor exosomes promote motility, invasion and cancer-initiating cell marker expression in pancreatic and colorectal cancer cells. Oncotarget. 2016:7:55409-36.

111. Yue S, Mu W, Erb U, Zoller M. The tetraspanins CD151 and Tspan8 are essential exosome components for the crosstalk between cancer initiating cells and their surrounding. Oncotarget. 2015;6:2366-84.

112. Zhao K, Erb U, Hackert T, Zoller M, Yue S. Distorted leukocyte migration, angiogenesis, wound repair and metastasis in Tspan8 and Tspan8/CD151 double knockout mice indicate complementary activities of Tspan8 and CD51. Biochim Biophys Acta, Mol Cell Res. 2018;1865:379-91.

113. Kyuno D, Bauer N, Schnolzer M, Provaznik J, Ryschich E, Hackert T, Zoller M. Distinct origin of claudin7 in early tumor endosomes affects exosome assembly. Int J Biol Sci. 2019;15:2224-39.

114. Linton SS, Abraham T, Liao J, Clawson GA, Butler PJ, Fox T, Kester M, Matters GL. Tumor-promoting effects of pancreatic cancer cell exosomes on THP-1derived macrophages. PLoS One. 2018;13:e0206759.

115. Zhang YF, Zhou YZ, Zhang B, Huang SF, Li PP, He XM, Cao GD, Kang MX, Dong $\mathrm{X}$, Wu YL. Pancreatic cancer-derived exosomes promoted pancreatic stellate cells recruitment by pancreatic cancer. J Cancer. 2019;10:4397-407.

116. Hoshino A, Costa-Silva B, Shen TL, Rodrigues G, Hashimoto A, Tesic Mark M, Molina H, Kohsaka S, Di Giannatale A, Ceder S, et al. Tumour exosome integrins determine organotropic metastasis. Nature. 2015;527(7578):329-35.

117. Shin SJ, Smith JA, Rezniczek GA, Pan S, Chen R, Brentnall TA, Wiche G, Kelly KA. Unexpected gain of function for the scaffolding protein plectin due to mislocalization in pancreatic cancer. Proc Natl Acad Sci U S A. 2013;110: 19414-9.

118. Nazarenko I, Rana S, Baumann A, McAlear J, Hellwig A, Trendelenburg M, Lochnit G, Preissner KT, Zoller M. Cell surface tetraspanin Tspan8 contributes to molecular pathways of exosome-induced endothelial cell activation. Cancer Res. 2010;70:1668-78.

119. Fahmy K, Gonzalez A, Arafa M, Peixoto P, Bellahcene A, Turtoi A, Delvenne $P$, Thiry M, Castronovo V, Peulen O. Myoferlin plays a key role in VEGFA secretion and impacts tumor-associated angiogenesis in human pancreas cancer. Int J Cancer. 2016;138:652-63.
120. Stefanius K, Servage K, de Souza SM, Gray HF, Toombs JE, Chimalapati S, Kim MS, Malladi VS, Brekken R, Orth K. Human pancreatic cancer cell exosomes, but not human normal cell exosomes, act as an initiator in cell transformation. Elife. 2019;8:e40226.

121. Shang D, Xie C, Hu J, Tan J, Yuan Y, Liu Z, Yang Z. Pancreatic cancer cellderived exosomal microRNA-27a promotes angiogenesis of human microvascular endothelial cells in pancreatic cancer via BTG2. J Cell Mol Med. 2020;24:588-604.

122. Wang X, Luo G, Zhang K, Cao J, Huang C, Jiang T, Liu B, Su L, Qiu Z. Hypoxic tumor-derived exosomal miR-301a mediates M2 macrophage polarization via PTEN/PI3Kgamma to promote pancreatic cancer metastasis. Cancer Res. 2018;78:4586-98.

123. Xia X, Zhang K, Luo G, Cen G, Cao J, Huang K, Qiu Z. Downregulation of miR-301a-3p sensitizes pancreatic cancer cells to gemcitabine treatment via PTEN. Am J Transl Res. 2017;9:1886-95.

124. Yu Z, Zhao S, Wang L, Wang J, Zhou J. miRNA-339-5p plays an important role in invasion and migration of pancreatic cancer cells. Med Sci Monit. 2019;25:7509-17.

125. Yin Z, Ma T, Huang B, Lin L, Zhou Y, Yan J, Zou Y, Chen S. Macrophagederived exosomal microRNA-501-3p promotes progression of pancreatic ductal adenocarcinoma through the TGFBR3-mediated TGF-beta signaling pathway. J Exp Clin Cancer Res. 2019;38:310.

126. Masamune A, Yoshida N, Hamada S, Takikawa T, Nabeshima T, Shimosegawa T. Exosomes derived from pancreatic cancer cells induce activation and profibrogenic activities in pancreatic stellate cells. Biochem Biophys Res Commun. 2018:495:71-7.

127. Gutkin A, Uziel O, Beery E, Nordenberg J, Pinchasi M, Goldvaser H, Henick S, Goldberg M, Lahav M. Tumor cells derived exosomes contain hTERT mRNA and transform nonmalignant fibroblasts into telomerase positive cells. Oncotarget. 2016;7(37):59173-88.

128. Li J, Li Z, Jiang P, Peng M, Zhang X, Chen K, Liu H, Bi H, Liu X, Li X. Circular RNA IARS (circ-IARS) secreted by pancreatic cancer cells and located within exosomes regulates endothelial monolayer permeability to promote tumor metastasis. J Exp Clin Cancer Res. 2018;37:177.

129. Li Z, Yanfang W, Li J, Jiang P, Peng T, Chen K, Zhao X, Zhang Y, Zhen P, Zhu $J$, et al. Tumor-released exosomal circular RNA PDE8A promotes invasive growth via the miR-338/MACC1/MET pathway in pancreatic cancer. Cancer Lett. 2018;432:237-50.

130. Costa-Silva B, Aiello NM, Ocean AJ, Singh S, Zhang H, Thakur BK, Becker A, Hoshino A, Mark MT, Molina H, et al. Pancreatic cancer exosomes initiate pre-metastatic niche formation in the liver. Nat Cell Biol. 2015;17:816-26.

131. Armacki M, Polaschek S, Waldenmaier M, Morawe M, Ruhland C, Schmid R, Lechel A, Tharehalli U, Steup C, Bektas Y, et al. Protein kinase D1, reduced in human pancreatic tumors, increases secretion of small extracellular vesicles from cancer cells that promote metastasis to lung in mice. Gastroenterology. 2020;S0016-5085(20):34705-3.

132. Satake T, Suetsugu A, Nakamura M, Kunisada T, Saji S, Moriwaki H, Shimizu M, Hoffman RM. Color-coded imaging of the fate of cancer-cell-derived exosomes during pancreatic cancer metastases in a nude-mouse model. Anticancer Res. 2019;39:4055-60.

133. Sun H, Rana S, Wang Z, Zhao K, Schnolzer M, Provaznik J, Hackert T, Lv Q Zoller M. The pancreatic cancer-initiating cell marker CD44v6 affects transcription, translation, and signaling: consequences for exosome composition and delivery. J Oncol. 2019;2019:3516973.

134. Morath I, Jung C, Leveque R, Linfeng C, Toillon RA, Warth A, Orian-Rousseau $\checkmark$. Differential recruitment of CD44 isoforms by ErbB ligands reveals an involvement of CD44 in breast cancer. Oncogene. 2018;37:1472-84.

135. Schmitt M, Metzger M, Gradl D, Davidson G, Orian-Rousseau V. CD44 functions in Wnt signaling by regulating LRP6 localization and activation. Cell Death Differ. 2015;22:677-89.

136. Jung T, Castellana D, Klingbeil P, Cuesta Hernandez I, Vitacolonna M, Orlicky DJ, Roffler SR, Brodt P, Zoller M. CD44v6 dependence of premetastatic niche preparation by exosomes. Neoplasia. 2009;11:1093-105.

137. Dong Y, Kang H, Liu H, Wang J, Guo Q, Song C, Sun Y, Zhang Y, Zhang H, Zhang $Z$, et al. Myoferlin, a membrane protein with emerging oncogenic roles. Biomed Res Int. 2019;2019:7365913.

138. Zhu W, Zhou B, Zhao C, Ba Z, Xu H, Yan X, Liu W, Zhu B, Wang L, Ren C. Myoferlin, a multifunctional protein in normal cells, has novel and key roles in various cancers. J Cell Mol Med. 2019;23:7180-9.

139. Rademaker G, Hennequiere $V$, Brohee L, Nokin MJ, Lovinfosse P, Durieux F, Gofflot S, Bellier J, Costanza B, Herfs M, et al. Myoferlin controls 
mitochondrial structure and activity in pancreatic ductal adenocarcinoma, and affects tumor aggressiveness. Oncogene. 2018;37:4398-412.

140. Leung C, Yu C, Lin MI, Tognon C, Bernatchez P. Expression of myoferlin in human and murine carcinoma tumors: role in membrane repair, cell proliferation, and tumorigenesis. Am J Pathol. 2013;182:1900-9.

141. Kugel S, Sebastian C, Fitamant J, Ross KN, Saha SK, Jain E, Gladden A, Arora KS, Kato Y, Rivera MN, et al. SIRT6 suppresses pancreatic cancer through control of Lin28b. Cell. 2016;165:1401-15.

142. Tamura A, Tsukita S. Paracellular barrier and channel functions of TJ claudins in organizing biological systems: advances in the field of barriology revealed in knockout mice. Semin Cell Dev Biol. 2014;36:177-85.

143. Harada T, Yamamoto H, Kishida S, Kishida M, Awada C, Takao T, Kikuchi A. Wnt5b-associated exosomes promote cancer cell migration and proliferation. Cancer Sci. 2017;108:42-52.

144. Bausch D, Thomas S, Mino-Kenudson M, Fernandez-del CC, Bauer TW, Williams M, Warshaw AL, Thayer SP, Kelly KA. Plectin-1 as a novel biomarker for pancreatic cancer. Clin Cancer Res. 2011;17(2):302-9.

145. Jin H, Liu P, Wu Y, Meng X, Wu M, Han J, Tan X. Exosomal zinc transporter ZIP4 promotes cancer growth and is a novel diagnostic biomarker for pancreatic cancer. Cancer Sci. 2018;109:2946-56.

146. Giovannetti E, van der Borden CL, Frampton AE, Ali A, Firuzi O, Peters GJ. Never let it go: stopping key mechanisms underlying metastasis to fight pancreatic cancer. Semin Cancer Biol. 2017:44:43-59.

147. Ma Y, Yu S, Zhao W, Lu Z, Chen J. miR-27a regulates the growth, colony formation and migration of pancreatic cancer cells by targeting Sprouty2. Cancer Lett. 2010;298:150-8.

148. Liu H, Ma Q, Xu Q, Lei J, Li X, Wang Z, Wu E. Therapeutic potential of perineural invasion, hypoxia and desmoplasia in pancreatic cancer. Curr Pharm Des. 2012;18:2395-403.

149. Patton MC, Zubair H, Khan MA, Singh S, Singh AP. Hypoxia alters the release and size distribution of extracellular vesicles in pancreatic cancer cells to support their adaptive survival. J Cell Biochem. 2019;121:828-39.

150. Zhai LY, Li MX, Pan WL, Chen Y, Li MM, Pang JX, Zheng L, Chen JX, Duan WJ. In situ detection of plasma exosomal microRNA-1246 for breast cancer diagnostics by a Au nanoflare probe. ACS Appl Mater Interfaces. 2018;10: 39478-86.

151. Bhagirath D, Yang TL, Bucay N, Sekhon K, Majid S, Shahryari V, Dahiya R, Tanaka Y, Saini S. microRNA-1246 is an exosomal biomarker for aggressive prostate cancer. Cancer Res. 2018;78:1833-44.

152. Hasegawa S, Equchi H, Nagano H, Konno M, Tomimaru Y, Wada H, Hama N, Kawamoto K, Kobayashi S, Nishida N, et al. MicroRNA-1246 expression associated with CCNG2-mediated chemoresistance and stemness in pancreatic cancer. Br J Cancer. 2014;111:1572-80

153. Kalluri R, Zeisberg M. Fibroblasts in cancer. Nat Rev Cancer. 2006;6:392-401.

154. Schoepp M, Strose AJ, Haier J. Dysregulation of miRNA expression in Cancer Associated Fibroblasts (CAFs) and its consequences on the tumor microenvironment. Cancers (Basel). 2017;9:54.

155. von Ahrens D, Bhagat TD, Nagrath D, Maitra A, Verma A. The role of stromal cancer-associated fibroblasts in pancreatic cancer. J Hematol Oncol. 2017;10:76

156. Zhao H, Yang L, Baddour J, Achreja A, Bernard V, Moss T, Marini JC, Tudawe $T$, Seviour EG, San Lucas FA, et al. Tumor microenvironment derived exosomes pleiotropically modulate cancer cell metabolism. Elife. 2016;5: e10250

157. Richards KE, Zeleniak AE, Fishel ML, Wu J, Littlepage LE, Hill R. Cancerassociated fibroblast exosomes regulate survival and proliferation of pancreatic cancer cells. Oncogene. 2017;36:1770-8.

158. Leca J, Martinez S, Lac S, Nigri J, Secq V, Rubis M, Bressy C, Serge A, Lavaut MN, Dusetti N, et al. Cancer-associated fibroblast-derived annexin A6+ extracellular vesicles support pancreatic cancer aggressiveness. J Clin Invest. 2016;126:4140-56

159. Chen Y, Song Y, Du W, Gong L, Chang H, Zou Z. Tumor-associated macrophages: an accomplice in solid tumor progression. J Biomed Sci. 2019;26:78.

160. Mimeault M, Batra SK. New advances on critical implications of tumor- and metastasis-initiating cells in cancer progression, treatment resistance and disease recurrence. Histol Histopathol. 2010;25:1057-73.

161. Salem KZ, Moschetta M, Sacco A, Imberti L, Rossi G, Ghobrial IM, Manier S, Roccaro AM. Exosomes in tumor angiogenesis. Methods Mol Biol. 2016; 1464:25-34.
162. Whiteside TL. Exosomes and tumor-mediated immune suppression. J Clin Invest. 2016:126:1216-23.

163. Zoller M. Exosomes in cancer disease. Methods Mol Biol. 2016;1381:111-49.

164. Greening DW, Gopal SK, Mathias RA, Liu L, Sheng J, Zhu HJ, Simpson RJ. Emerging roles of exosomes during epithelial-mesenchymal transition and cancer progression. Semin Cell Dev Biol. 2015;40:60-71.

165. Wang Z, Sun H, Provaznik J, Hackert T, Zoller M. Pancreatic cancer-initiating cell exosome message transfer into noncancer-initiating cells: the importance of CD44v6 in reprogramming. J Exp Clin Cancer Res. 2019;38: 132.

166. Kyuno D, Zhao K, Schnolzer M, Provaznik J, Hackert T, Zoller M. Claudin7dependent exosome-promoted reprogramming of nonmetastasizing tumor cells. Int J Cancer. 2019;145:2182-200.

167. Kyuno D, Zhao K, Bauer N, Ryschich E, Zoller M. Therapeutic targeting cancer-initiating cell markers by exosome miRNA: efficacy and functional consequences exemplified for claudin7 and EpCAM. Transl Oncol. 2019;12: 191-9.

168. Pothula SP, Pirola RC, Wilson JS, Apte MV. Pancreatic stellate cells: aiding and abetting pancreatic cancer progression. Pancreatology. 2020;20:409-18.

169. Takikawa T, Masamune A, Yoshida N, Hamada S, Kogure T, Shimosegawa T. Exosomes derived from pancreatic stellate cells: microRNA signature and effects on pancreatic cancer cells. Pancreas. 2017:46:19-27.

170. Erb U, Zhao K, Wang Z, Xiao L, Zoller M. Murine and human pancreatic tumor exosome recovery in mouse serum: diagnostic and prognostic potential and target cell delivery. Cancer Lett. 2017:403:1-12.

171. Kanchanapally R, Deshmukh SK, Chavva SR, Tyagi N, Srivastava SK, Patel GK, Singh AP, Singh S. Drug-loaded exosomal preparations from different cell types exhibit distinctive loading capability, yield, and antitumor efficacies: a comparative analysis. Int J Nanomedicine. 2019;14:531-41.

172. Beloribi S, Ristorcelli E, Breuzard G, Silvy F, Bertrand-Michel J, Beraud E, Verine A, Lombardo D. Exosomal lipids impact notch signaling and induce death of human pancreatic tumoral SOJ-6 cells. PLoS One. 2012;7:e47480.

\section{Publisher's Note}

Springer Nature remains neutral with regard to jurisdictional claims in published maps and institutional affiliations.

Ready to submit your research? Choose BMC and benefit from:

- fast, convenient online submission

- thorough peer review by experienced researchers in your field

- rapid publication on acceptance

- support for research data, including large and complex data types

- gold Open Access which fosters wider collaboration and increased citations

- maximum visibility for your research: over $100 \mathrm{M}$ website views per year

At BMC, research is always in progress.

Learn more biomedcentral.com/submissions 